\title{
Male Infertility and Psychological Repercussions: A Neglected Problem in Northern Upper Egypt
}

\author{
Wafaa Mostafa Ahmed Gamel ${ }^{1}$, Hanan Elzeblawy Hassan ${ }^{2}$ \& Alyaa Abdallah El-ezazy ${ }^{3}$ \\ ${ }^{1}$ Maternal and Neonatal Health Nursing, Faculty of Nursing, Fayoum University, Egypt \\ ${ }^{2}$ Maternal and Newborn Health Nursing, Faculty of Nursing, Beni-Suef University, Egypt \\ ${ }^{3}$ Psychiatric and Mental Health Nursing, Faculty of Nursing, Beni-Suef University, Egypt \\ Correspondence: Hanan Elzeblawy Hassan, Maternal and Newborn Health Nursing Department, Faculty of \\ Nursing, Beni-Suef University, Egypt.
}

Received: July 17, 2019

doi:10.20849/ijsn.v4i4.654
Accepted: September 17, $2019 \quad$ Online Published: October 8, 2019

URL: https://doi.org/10.20849/ijsn.v4i4.654

\begin{abstract}
Background: Infertility, although not a life-threatening illness, is a life crisis that leads to medical, psychological, social and ethical issues. Male infertility is a neglected area of research, particularly, in Upper Egypt. Most of the studies carried out on this issue, mainly, focused on the etiological factors associated with infertility. The vast majority of researcher studied infertility as a causative or result of psychological aspects but little study psychological aspects as reactive or effect of infertility. Aim: This study shed some light on the extent of psychological repercussions, which was negatively impacted on through the male infertility experience, in Northern Upper Egypt. Method: A descriptive cross-sectional study was performed on 50 infertile men in governmental hospitals in Fayoum, Egypt. A structured questionnaire comprises 2 parts was used: (1) sociodemographic characteristics, participants' lifestyle, and sexual behavior \& infertility history, (2) Depression-Anxiety-Stress-Scale-42 (DASS 42). Results: The results of the present study portrayed that $42 \%$ of the studied subjects were having a sever level of depression. However, $36.0 \%$ had a moderate level of anxiety. Moreover, $46.0 \%$ of the subject had severe tension. To sum up, infertility has many implications for the psychological state of infertile men. Men's psychosocial status was influenced by the type and duration of infertility treatment. Conclusion: Concluding we will have to admit that Upper Egyptian men appear to develop psychological distress when facing infertility and that this is a construct overly influenced by sociodemographic characteristics, lifestyle and sexual pattern supported by our research results. Recommendations: Our findings reinforce the need for andrologist, gynecologist, and infertility specialist and health care sectors as well as psychological professionals to look for psychosocial issues in men undergoing infertility treatment. Further research is needed to understand the association between psychosocial issues and fertility outcomes, as well as effective psychosocial interventions.
\end{abstract}

Keywords: male infertility, psychological repercussions, psychological aspects, depression, anxiety, tension

\section{Introduction}

Infertility has been a major medical/social preoccupation since the dawn of human existence. ${ }^{[1]}$ In the second decade of the new millennium, infertility remains a highly prevalent global condition. Infertility is estimated to affect between $8.0 \%$ and $12.0 \%$ of reproductive-aged couples worldwide, with $9.0 \%$ currently cited as the probable global average. ${ }^{[2]}$

The American Society for Reproductive Medicine (ASRM) describes infertility as the result of a disease (an interruption, cessation, or disorder of systems/organs/body functions) of the male or female reproductive system which, in turn, prevent the conception of a child. The duration of unprotected intercourse with failure to conceive should be about, at least, 1 year before an infertility evaluation is undertaken, unless medical history, age, or physical findings dictate earlier evaluation and treatment. ${ }^{[3-8]}$

In the last 50 years, a significant decrease in human fertility has been observed. Current literature has also been indicated $15.0 \%$ of couples experience difficulties conceiving. Among infertile couples; the male partner is the responsible one for $50.0 \%$ cases of infertility. ${ }^{[2,4,9,10,11]}$ However, other literature indicated that in around $30.0 \%$ to $40.0 \%$ of infertile couples the male partner is the sole cause or contributing cause of infertility. ${ }^{[8,12,13]}$ 
In most cases, there are no obvious signs/symptoms of infertility. Intercourse and erections, as well as, ejaculation will usually happen without any difficulties. The quantity/appearance of the ejaculated seminal fluid, generally, appears normal to the naked eye. ${ }^{[14]}$ Medical tests and laboratory investigations will be needed to find out if a man is infertile. ${ }^{[15]}$

Male infertility is a complex disorder and multifactorial conditions process that affects a large sector of the population, with a number of potential contributing causes; however, many of its etiological factors are still unknown. ${ }^{[5,16]}$ Male infertility may be explained by several factors, including many, but not all, of which can be identified and treated. When the causes of abnormal semen parameters can't be identified as in many patients, this condition is termed idiopathic. ${ }^{[17,18]}$

Male infertility is usually caused by problems that may affect either sperm production and/or transport. A man's fertility generally relies on the quantity and quality of his sperm. ${ }^{[14]}$ Many men with male factor infertility have suboptimal semen quality. ${ }^{[4]}$ About $2 / 3$ of infertile males have a sperm production problems in their testes. Either a low number of sperms is made and/or the sperms that are made doen't work properly. ${ }^{[14,15]}$

The following terms have been developed to describe conditions in which one or more of these factors are abnormal; aspermia (the patient produces no semen), azoospermia (the patient produces semen containing no sperm), oligozoospermia/oligospermia (sperm concentration is low, less than 15 million per/ml), asthenozoospermia/asthenospermia (less than $40.0 \%$ of the sperm are moving, and less than $32.0 \%$ are swimming progressively), teratozoospermia (less than $4.0 \%$ of the sperm are normally shaped), oligo-asthenoterato-zoospermia (sometimes referred to as QAT) syndrome (less than 15 million sperm per ml with less than $40.0 \%$ being motile and less than $4.0 \%$ are normally shaped), necrospermia (all sperm are dead poor viability and less than $58.0 \%$ are alive), pyospermia or leucospermia (presence of large number of white blood cells (more than one million/ml) in the semen, often associated with an infection. ${ }^{[11]}$ If the number of spermatozoa a man ejaculates is low, decreased sperm motility, and/or morphology is present in at least one sample of two sperm analyses, collected one-to-four weeks apart", if the sperms are of a poor quality, or if there is alteration in sperm concentration, ${ }^{[14,19,20]}$ it will be difficult, and sometimes impossible, for him to cause a pregnancy. ${ }^{[14]}$

The actual etiology of male infertility is still poorly understood. The known causes of male infertility may be either genetic or physical. ${ }^{[11]}$ Many environmental agents can adversely affect germ cell development at many different stages from proliferating spermatogonia to mature spermatozoa ${ }^{[21]}$, Chromosomal/genetic causes as Klinefelter's syndrome, Y chromosome deletions, other genetic problems, such as Down syndrome (15.00\% to $30.00 \%$ of male factor infertility) ${ }^{[14,16]}$, undescended testes (failure of one or both testes to descend in the scrotum at birth), heat, torsion (twisting of one or both testes in the scrotum), prostate-related-problems, varicocele (varicose veins in the testes), infection, medicines, chemicals and/or radiation damage, unknown or idiopathic, absence of vas-deferens, and physiological factors, including oxidative stress induced by reactive-oxygen-species (RQS), have been implicated. ${ }^{[4,14,15,16,19,22]}$

Blockage of sperm transport (sperm-transport-problems) are found in about 1 in every 5 infertile men, including men who have had a vasectomy but now wish to have more children. Blockages (often referred to as obstructions) in the tubes leading sperm away from the testes to the penis can cause a complete lack of sperm in the ejaculated semen. Blockages may be attributed to infections like Chlamydia and sexually transmitted diseases (STDs), prostate-related problems, absence of vas deferens, and vasectomy. ${ }^{[14,15,22]}$

Other less common causes of male infertility include sexual problems, hormonal problems, and sperm antibodies: (1) Sexual problems (erection and/or ejaculatory problems) that affect whether semen abilityto enter the woman's vagina for fertilization to take place. It may be attributed to retrograde/premature ejaculation, retarded or inhibited/failure of ejaculation, erectile dysfunction, infrequent intercourse, spinal cord injury, prostate surgeries, nerves damage, some medicines ${ }^{[7,14,15]}$; (2) Hormonal problems as pituitary tumors or congenital lack of LH/FSH (Pituitary problems), and anabolic (androgenic) steroid abuse. Low levels of hormones made in the pituitary gland that act on the testes; (3) Sperm antibodies which may be caused by vasectomy, injury or infection in the epididymis. Chlamydia can reside in the epididymis and vas deferens, affecting sperm development and fertility, and unknown cause. Sperm-antibodies, in most men, will not affect the chances of pregnancy but in some men sperm antibodies reduce fertility. ${ }^{[5,14,15]}$

Lifestyle, as well as general health issues, can be contributing factors of male infertility. Healthy sperm function can be negatively affected by poor or malnutrition, lack of exercise as well as alcohol consumption and drug abuse. Stress and obesity are, also, considered contributing factors to male infertility. ${ }^{[3]}$ Parallel to the global increase in obesity is the reported world decrease in male fertility and fecundity. Interestingly, men with 
increased BMI were significantly more likely to be infertile than normal-weight men. According to Carlson et al., the quality of semen has substantially declined, which has subsequently lead to decreased male fertility. This could likely contribute to overall reduced male reproductive potential. In addition, there is also a significant increase in the incidence of obesity in patients with male-factor infertility, and couples with obese male partners are more likely to experience subfecundity, a correlation that seems necessary to address. Due to the fact that this decline has occurred in close parallel with increasing rates of obesity, it is necessary to focus on the possibility of obesity as an etiology of male infertility and reduced fecundity. ${ }^{[4]}$ In relation to general health, age can be a factor as sperm quality begins to decrease in men over the age of 40 years old. ${ }^{[3,18]}$

As there are many causes of male infertility, there are also many types of treatment for affected men to help them conceive a child. For infertile men, these treatments generally include addressing the issues surrounding sexual function and increasing sperm count with medication. ${ }^{[3]}$

However, there is no known specific medication for the treatment of male infertility in modern medicine, the available options of male infertility management ethier medical as the administration of certain drugs to improve quality of semen or surgical treatment. The different assisted reproduction techniques (ART) are often related to issues of efficacy, cost, ease of use or administration, and its side effects. Also, legal, cultural and religious inquiries have limited the available choices in developing countries. According to the World Health Organisation (WHO) survey, $70.00 \%$ to $80.00 \%$ of the world populations rely on non-conventional medicine in their primary healthcare. Therefore, there is a renewed interest towards oriental medicines, such as Shilajit, Black musli, and Ashwagandha which are being constantly claimed as an aphrodisiac and used by traditional healers of Asian countries for male infertility treatment. ${ }^{[9]}$

Dramatic advances in the diagnostic meaures and treatment of male infertility allow conception for couples previously considered untreatable. Elucidation of the genetics of male infertility and new tests of sperm function have led to a better understanding of the etiologies and prognosis for treatment of the infertile male. Although the advent of invitro-fertilization combined with intracytoplasmic sperm injection (IVF/ICSI) has revolutionized the treatment of male factor infertility ${ }^{[23]}$, undergoing ART treatment creates many physical/economic/emotional burdens. ${ }^{[13]}$ Assisted conception treatment such as IVF may enable infertile men to achieve a pregnancy with his own sperm, however, they will still be infertile and will need assistance if they wish to have more children. ${ }^{[1]}$ Patients with Klinefelter-syndrome may try to achieve pregnancy by ICSI but they risk producing offspring with chromosomal-abnormalities. ${ }^{[16]}$

The most prevalent psychological treatment is counseling as well as marriage therapy. A lot of men believe that there are numerous disincentives to psychological treatment despite its potential benefits, especially for those forms of infertility most linked to psychological and behavioral factors. Men are much less likely to seekout psychological help than women. Man, who acknowledge infertility, articulates the sources of his anxiety, expresses his loss of self-confidence in sexual adequacy, deals openly with his wives' disappointment and anger, and consciously redefine his male/marital roles show improved sperm count and may even be more successful at impregnating their wives. There is an important role of psychoanalytic treatment when dealing with male infertility. ${ }^{[24]}$

Need to have a child is an inherent need in all humans. ${ }^{[25]}$ As reproduction is believed to be one of the main basic necessities of humans, a psychological crisis may occur when something interferes with their ability to reproduce. ${ }^{[12]}$ Previous studies indicate that $20.0 \%$ of infertile males are at risk for emotional problems during treatment. In addition, hormonal changes during treatment may also affect the emotions of infertile men. When a male feel powerless and experiences low self-esteem, he will try to reclaim it through aggressive behaviors. ${ }^{[26]}$ Only $20.00 \%$ of patients seek psychosocial intervention and support. ${ }^{[27]}$

In the mid-1980s clinicians and researchers began questioning the hypothesis that psychological distress caused infertility. Instead of this, they had found that psychological distresses were consequences of infertility. That is why psychological/mental health professionals have become increasingly involved in the provision of care to infertile patients. ${ }^{[6]}$ Despite the endless medical \& nursing research of infertility, the psychological aspects of infertility haven't been adequately addressed. Written and documented reports on infertility are voluminous and have illustrated that involuntary childlessness may be emotionally withering, and it may involve a stronger psychologic distress. This distress may affect the relationship between a husband and his wife. The infertile individual usually experiences numerous emotional consequences as depression, anxiety, and stress. ${ }^{[12]}$

Infertility is a serious psychological trauma and a terrible emotional distress for infertile man. ${ }^{[28]}$ When the psychological-implications-related-to-human-infertility had been extensively studied, several reviews address depressive symptoms, stress \& anxiety in relation to fertility. ${ }^{[12,29,30]}$ Whether depression may be caused by 
infertility, or the co-occurrence of these two phenomena is coincidental, is not clear. Some researchers have suggested that outcomes of infertility treatment might be enhanced by effectively treating co-occurring depression. ${ }^{[1,31]}$ Masoumi et al (2013) reported that depression is a common mental disorder affecting about 121 million infertile people worldwide. ${ }^{[28]}$

Previous studies reported that the childless man of reproductive age has desires to experience parenthood that is similar to that of his female counterparts. In addition, diagnosis, as well as, treatment initiation will be associated with elevated infertility-specific-anxiety. Moreover, unsuccessful treatment may be a leading factor to a state of lasting sadness. An infertile man will be more vulnerable to severe anxiety. ${ }^{[26,32]}$

While stress perse doesn't cause infertility, infertility may cause stress. The stress which is connected to the holistic issues of infertility may create and intensify partner conflicts. ${ }^{[33]}$ The relationship between infertility and stress can be viewed as either causative (where stress causes infertility) or reactive (where infertility causes stress). The subject areas in which researchers have analyzed the possibility that stress causes infertility have been found to negate each other. Some subject indicated a relationship \& others do not. ${ }^{[12]}$

Although infertility is considered a stressful event, for most individuals, it is clear from the previously written literature that infertility is more devastating for some individuals than for other ones. Stress should be high only when the situation is perceived as harmful or threatening, and the individuals feel that they have insufficient resources to cope effectively. ${ }^{[8]}$

\subsection{Significance of the Study}

While there is an emerging body of evidence focused on the psychological/social/psychosocial aspects of infertility for men, knowledge gap is still had a significant remaining. As most studies carried out at clinical services, little is known about men who don't seek treatment. Among those who do pursue treatment, the influencing factors that may affect the decision to discontinue treatment are ambiguous and unknown. The psychological aspects of treatment including experiences of invasive investigations or of witnessing their partners undergoing procedures haven't been described. The main factors which may govern the decision to either become a parent through adoption or to live without kids among infertile men, in couples who elect not to pursue infertility treatment, are also ambiguous and unknown. Subfertile man's reaction when spontaneous conception occurs unexpectedly hasn't yet been studied. There is some evidence concerning female's experience of pregnancy and early parenthood after assisted conception, but none about man's reaction to and needs during these experiences. ${ }^{[32]}$

Many investigators and researchers have tried to demonstrate a causal-link between psychopathology and infertility, but the results were contradictory. With more researches in the field of infertility, gradually theorists were able to conclude that infertility leads to psychogenic causes. Infertility is often experienced as a bio-psychosocial crisis accompanied by adverse cognitive-behavioral and affective-outcomes, such as over-generalization of the loss of control over reproduction to other aspects of life, hopelessness, feelings of unfulfillment, inability to plan for the future and compromised ability to find alternate goals and meaning in life, social withdrawal, anxiety, and depression. ${ }^{[6]}$

Few studies reported whether male-specific cutoff scores were used to identify the prevalence of clinically significant psychological conditions, in particular, anxiety and depression. However, comparisons with test norms indicate that apart from situation-specific anxiety, the prevalence of depression and anxiety appears to be the same in men affected by infertility as in the general population. In order to understand man's needs more fully, other relevant dimensions of psychological aspects and functioning, including experience of grief/shame, warrant systematic investigation. ${ }^{[32]}$

Man prefers oral to written treatment information, moreover, prefers to receive emotional support from infertility clinician rather than from psychological/mental health professional, self-help support groups or friends. ${ }^{[32]}$ Male infertility is a one of the neglected areas of research in Upper Egypt. Most of the studies carried out on this issue mainly focus on the etiological factors associated with infertility. The andrologist and urologist are often responsible for the assessment of male patients with infertility. The vast majority of researcher studied infertility as a causative or result of psychological aspects but little study psychological aspects as reactive or effect of infertility. Psychological issues of infertility in man have had been a matter of significantly less research than that in woman. Most of the existing studies investigated a woman's reaction to male infertility, while few studies examined couples facing male's infertility and the psychological experiences of men. ${ }^{[10,32]}$ However, the psychological issue of this disorder and its treatment is often neglected. Health is not only about physical well-being, but it also involves both social and psychological well-being. Studies have demonstrated that psychological distress doesn't only interfere with one's quality of life, but also results in a high dropout rate 
among individuals with infertility presenting for assessment and treatment. ${ }^{[34]}$ Little attention has been paid to the psychological issues of infertile man from developing countries who have been traditionally stigmatized as feeble and ineffective. ${ }^{[39]}$ Surprisingly, there are few studies which have carefully assessed this relationship in Arab and no studies conducted in Upper Egypt. This study shed some light on the extent of psychological issues which was negatively impacted on through the male infertility experience in Upper Egypt and demonstrate the need for psychological assessment to be included in the assessment of male infertility.

\subsection{Operational Definitions}

Infertility: Infertility has been defined by the World Health Organization (WHO) as the inability to conceive (involuntarily childless) despite regular sexually active (sexual intercourse; 4-5 times per week), sustained for a period exceeding 12 months without the use of any contraceptive methods. ${ }^{[1,12,20,40,41,42]}$ It is important to note that infertility is simply a decrease in the ability to conceive, not the inability to conceive, which would indicate sterility ${ }^{\left[{ }^{[3]}\right]}$ Words used in the dictionary to describe infertile are "unproductive", "not capable" and "barren". ${ }^{[3]}$

Primary Infertility: never having fathered a pregnancy. ${ }^{[6,17]}$

Secondary Infertility: having previously fathered a pregnancy. ${ }^{[6,17]}$

Assisted Reproductive Technologies (ART): Assisted reproductive technologies (ART) include Invetro fertilization (IVF) and intracytoplasmic sperm injection (ICSI). ART doesn't cure or treat the cause of infertility but they can help couples achieve pregnancy. ${ }^{[14]}$

In-vitro fertilization (IVF): IVF is a form of ART where sperm collected from the male are mixed with eggs from the female partner outside her body. Fertility drugs should be given to the female partner to produce and increase the number of ova that are removed surgically from a woman's ovary. ${ }^{[14]}$

Intracytoplasmic Sperm Injection (ICSI): Intracytoplasmic sperm injection (ICSI) is a form of IVF where a single sperm is placed directly into each egg by piercing the outer covering of the ovum. ICSI is particularly helpful for a man with poor sperm production. Sperms can be collected from the seminal fluid or removed carefully from man's testis or epididymis. ICSI can achieve pregnancy even when only few sperms are produced. As for IVF, after fertilization, the resulting embryos are then placed into the woman's uterus. ${ }^{[14,15]}$

Psychological Aspects: The psychological aspect of infertility refers to the study of psychological changes that may occur after being diagnosed with infertility. ${ }^{[26]}$

Depression: Depression is a common mental disorder that presents with depressed mood, loss of pleasure, feeling of guilt/low self-stem, disturbed sleep/appetite, low energy, and poor concentration. ${ }^{[28]}$

Anxiety: State anxiety describes a state of the mind and experience of unpleasant effect which develops depending on environmental stimulants that are perceived by the individuals as being dangerous or threatening when confronted with specific situations, demands or a particular object or event. ${ }^{[44,45]}$

Psychological Stress: Stress is defined as a real or perceived threat from internal or external adverse events (or stressors) to the homeostasis or well-being of an organism. Psychological stress in human was defined as any uncomfortable emotional experience accompanied by predictable biochemical/physiological/behavioral changes or responses. In physiological terms, psychological stress is a chain of events leading to the disruption of homoeostasis as a result of the direct effect of stress on the mind. Stress is a byword in modern life, which is a mishmash of personal ambitions, hassles, deadlines, demands, and frustrations. ${ }^{[3,46]}$

\subsection{Aim of the Study}

The vast majority of researchers studied infertility as a causative or result of psychological aspects but little study psychological aspects as reactive or effect of infertility. Moreover, Research concerning the psychosocial aspects of infertility and infertility focuses more often on women than men; so, the aim of this study was to evaluate the existing and concerning the psychosocial aspects (depression, anxiety, and stress) of male-related infertility and explore the implications of socio-demographic and lifestyle correlates in a sample of Upper Egyptian infertile men.

\subsection{Research Questions}

Are psychosocial aspects (depression, anxiety, and stress) is affected by infertility among infertile male in Upper Egypt?

Are socio-demographic, and lifestyle significantly implicated in men's psychological aspects among male-related infertility in Upper Egypt? 


\section{Subjects and Methods}

\subsection{Research Design}

A descriptive cross-sectional study was performed on 50 infertile men to appraise the relationship between infertility and psychological implication among infertile men in Upper Egypt mainly Fayoum city, Egypt.

\subsection{Research Setting}

This study encompassed governmental hospitals in Fayoum City, Egypt:

a. University Hospital (infertility, andrology and urology clinic).

b. General Hospital, which affiliates to Ministry of Health (infertility, andrology and urology clinic).

\subsection{Subjects}

The sample for this study was comprised of 50 convenient men, diagnosed with infertility, who were referred to previously mentioned settings for infertility assessment and evaluation of the infertility factor.

\subsubsection{Inclusion Criteria}

- Have had diagnosed with primary or secondary infertility.

- Have unsuccessfully tried to conceive a child with natural methods for $\geq 12$ months.

- Has one year of regular unprotected intercourse.

\subsubsection{Exclusion Criteria}

- Unwillingness or refused to participate in the study.

- Diagnosed as having any other psychological, psychiatric disorder (had pre-existing psychiatric morbidity).

- Those who were on psychotropic medications

\subsection{Tool of Data Collection}

In order to obtain the necessary information from the participants; a structured questionnaire with the following mentioned parts was designed by the researchers after reviewing the related-literature.

The first part: personal, sociodemographic characteristics, participants' lifestyle and sexual behavior, and reproductive $\&$ infertility history. It contains 3 -sections as the following mentioned:

Section I: personal data such as age, educational level, marital status, age at marriage \& duration of marriage, job status \& type, and family type, residence, and income adequacy.

Section II: a review of lifestyle exposures (weight, nutrition, sleeping pattern, smoking status \& duration).

Section III: The reproductive and infertility history should include, however, sexual behavior (coital frequency/timing), cause and duration of infertility, previous fertility doesn't exclude, male infertility factor, and type \& duration of infertility treatment also involved.

The second part: Depression-Anxiety-Stress-Scale-42 (DASS 42). ${ }^{[47-53]}$ The DASS is a 42-items-self-report inventory, designed to measure the magnitude, that yields 3 negative emotional factors: Depression; Anxiety; and Stress. This screening and outcome measure reflects the past 7 days.

I. The depression subscale includes some items which measure one's features, like an hedonia, sadness, life futility, worthlessness, hopelessness, unable to become enthusiastic, difficult to work up initiative, lack of energy, lack of self-confidence and nothing to look forward.

II. Anxiety subscale composes of items which can evaluate physiological arousal, phobias, and situational anxiety.

III. Stress subscale composes of items, such as difficulty in achieving relaxation, state of nervous tension/agitation/overreaction to situations, irritability, and restlessness.

\subsubsection{Scoring System}

A respondent indicates (subjects should rate the severity/frequency of the symptom during the last week) on a 4-degree scale (from 0 to 3). Each subscale of stress, anxiety, and depression has 14 items, and participant's score in each subscale is obtained by the sum of all items related to a subscale.

The rating scale is briefly summarized as follows:

- "0" Never "Didn't apply at all". 
- $\quad 1 "$ Sometimes" Applied to some degree or some of the time ".

- $\quad$ "2" Often" Applied to a considerable degree, or a good part of the time ".

- "3" Almost Always" Applied very much, or most of the time ".

\begin{tabular}{cccc}
\hline \multirow{2}{*}{ Level } & \multicolumn{2}{c}{ Classification of psychological distress (Total Score) } \\
\cline { 2 - 4 } & Depression & Anxiety & Stress \\
\hline No/Normal & $0-2$ & $0-2$ & $0-2$ \\
\hline Mild & $3-6$ & $3-6$ & $3-6$ \\
\hline Moderate & $7-10$ & $7-10$ & $7-10$ \\
\hline Severe & $11-14$ & $11-14$ & $11-14$ \\
\hline
\end{tabular}

\subsection{Methods of Data Collection}

This study was covered in the following phases:

\subsubsection{Validity of Tool}

Evidence has been found for constructing and convergent validity for the anxiety and depression subscales of the long versions of the DASS. ${ }^{[48,49,54]}$

\subsubsection{Reliability}

The reliabilities of DASS on the basis of Cronbach Alpha were 0.93 for subscales depression, 0.85 for anxiety and 0.87 for stress. ${ }^{[40,54]}$

\subsubsection{Administrative Considerations}

Approval was taken from hospitals directors before taking up the research. Written letters, describing the purpose of the study were issued from the dean of the faculty of nursing, Fayoum University, to the directorate of the all previous mentioned settings to obtain the permit to gather the research sample from hospitals under their directorate.

\subsubsection{Ethical Considerations}

The agreement for participation of the subjects was taken after the researchers explained the aim of the study. They were given an opportunity to refuse the participation or withdrawal at any stage of the research. They were assured that the information would be confidential and used for the research purpose only.

\subsubsection{Pilot Study}

The pilot study included about $10 \%$ (5 participants) of the study sample.

\subsubsection{Field Work}

Researchers approached 105 men in the previously mentioned clinics and ask them to participate in the study, 55 men $(52.3 \%)$ agreed to take part but finally, only 50 men $(90.9 \%)$ completed questionnaires. Participants were asked to complete the self-rating questionnaires separately. The researcher helped illiterate ones to complete the questionnaire. Subjects were diagnosed as infertile by an experienced infertility specialist, completed the socio-demographic characteristics questionnaire and the depression, anxiety and stress scale (DASS, 42), a self-report-questionnaire. Each participant took about 50-65 minutes to complete the questionnaire. Data were collected over a one year period, between April 2018 and March 2019.

\subsubsection{Statistical Design}

Proper statistical tests were applied to decide whether there was a significant difference or not, using the statistical package for social science (SPSS), version 16.0 (SPSS, Chicago, IL, USA). The following statistical measures were used:

- Descriptive measures included count $(\mathrm{N})$, percentage $(\%)$, arithmetic mean, standard deviation (Mean \pm SD).

- Relations between different numerical variables were tested using Pearson correlation.

- Statistical tests included Chi-square $\left(\chi^{2}\right)$ test for analysis of qualitative variables.

- The graphical presentation included Bar chart diagram. 
- The level of significance selected for this study was P equal to or less than 0.05 .

\section{Results}

A total of 105 infertile men were recruited into the study. Of the 50 males included in the study, the mean age of the interviewees was $39 \pm 13.84$ years, of whom $10(20.0 \%)$ were less than 25 years age group, $5(10.0 \%)$ were in the 25-35 years age group, $17(34.0 \%)$ were in the 35-45 year age group and $18(36.0 \%)$ had an age of $>45$ years. Age of the $1^{\text {st }}$ marriage and duration of the current marriage of our participants were $21.5 \pm 2.67,5.2 \pm$ 4.42 years respectively. Among the interviewees male included in the current study, 19 (38.0\%) were urbanites and $31(62.0 \%)$ were from rural areas, $25(50.0 \%)$ of them haven't an adequate family income (Table 1).

The detailed lifestyle of A total of 50 participated males is represented in Table 2. All the respondents were smokers, the duration of smoking was $6.32 \pm 7.67,20.0 \%$ of them were overweight, $80.0 \%$ had an irregular sleeping pattern at night. Moreover, $16.0 \%$ had inadequate diet and $56.0 \%$ their sexual pattern were less than 4 times/week.

It is evident from Table 3 that the main cause of infertility was sperm production problems (36.0\%) followed by blockage of sperm transport $(28.0 \%)$ while hormonal problems present $20.0 \%$ of male-related infertility and sexual problems (erection and ejaculatory problems) presents $14.0 \%$ of causes of infertility. However, it was noticed that only $2.0 \%$ of infertility was related to sperm antibodies. The mean duration of infertility was $13.7 \pm$ $4.12,84.0 \%$ of the studied subject suffered from primary infertility. The vast majority of them (90.0\%) expanded more than 5 years in infertility treatment; $80.0 \%$ of them by traditional treatment, and only $20.0 \%$ by assist reproductive technology (ART).

Distribution of levels of depression, anxiety, and tension are portrayed in Figure 1. As the figure depicts that more than half $(54.0 \%)$ of the studied subjects were having a moderate level of depression and $42.0 \%$ of them had a sever level. However, $36.0 \%$ had a moderate level of anxiety, and $30.0 \%$ had a sever level. Moreover, $46.0 \%$ of the subject had a severe tension and $40.0 \%$ had a moderate level.

Table 4 summarizes the relationship between psychological repercussions and the sociodemographic and family characteristics of the studied subjects. A highly statistically significant difference in depression, anxiety \& tension amongst infertile male in relation to their educational qualification, occupation type, marital status, age at marriage, number and duration of marriages as well as family income adequacy. However, there was no statistical statistically difference in psychological issues (except in anxiety $\mathrm{P}=0.001$ ) amongst those infertile males in relation to their residence.

The relationship between the studied sample according to their lifestyle and sexual characteristics and their association with psychological status is presented in Table 5. As shown, there were no significant differences between depression of infertile men in their reported patterns of lifestyle and sexual activity. However, there was no statistically significant difference in anxiety level amongst those infertile males in relation to their nutritional and sexual pattern $(\mathrm{P}=0.330 \& 0.231$, respectively), there is a significant association with duration of smoking (yrs), weight (body mass index "BMI") and sleeping pattern at night. Additionally, a significant difference in tension amongst those infertile males in relation to all mentioned items of their lifestyle and sexual pattern except in sleeping pattern at night; which its $\mathrm{P}$ value recorded 0.117 .

The association between depression, anxiety \& tension of the studied infertile men and their infertility history are presented in Table 6. This table illustrated a statistically significant impact of causes, duration, type of infertility, type \& duration of treatment as well as the gender of children in secondary infertility of infertility on tension level. However, a statistically significant difference was observed between causes, duration of treatment and gender of children in secondary infertility of infertility on depression level. The same table presents a statistically significant association between causes, duration, type \& duration of treatment of infertility on anxiety level. 
Table 1. Distribution of the studied sample according to their sociodemographic and family characteristics $(\mathrm{N}=$ 50)

\begin{tabular}{|c|c|c|}
\hline Socio demographic characteristics & Frequency & Percent $\%$ \\
\hline \multicolumn{3}{|l|}{ Age } \\
\hline$<25$ & 10 & $20 \%$ \\
\hline $25-$ & 5 & $10 \%$ \\
\hline $35-$ & 17 & $34 \%$ \\
\hline $45-$ & 18 & $36 \%$ \\
\hline Mean \pm SD & $39 \pm 13.84$ & \\
\hline \multicolumn{3}{|l|}{ Educational level } \\
\hline Illiterate & 9 & $18 \%$ \\
\hline Primary education (read and write) & 9 & $18 \%$ \\
\hline Secondary education or equal & 24 & $48 \%$ \\
\hline University education & 8 & $16 \%$ \\
\hline \multicolumn{3}{|l|}{ Occupation type } \\
\hline Craftsman & 8 & $16 \%$ \\
\hline Officer (employee) & 18 & $36 \%$ \\
\hline Farmer & 13 & $26 \%$ \\
\hline Driver & 10 & $20 \%$ \\
\hline Other job & 1 & $2 \%$ \\
\hline \multicolumn{3}{|l|}{ Marital status } \\
\hline Single & 4 & $8 \%$ \\
\hline Married & 12 & $24 \%$ \\
\hline Divorced & 16 & $32 \%$ \\
\hline Separated & 8 & $16 \%$ \\
\hline Cohabiting & 10 & $20 \%$ \\
\hline \multicolumn{3}{|l|}{ Age at $1^{\text {st }}$ marriage } \\
\hline$<20$ years & 22 & $44 \%$ \\
\hline 20- years & 28 & $56 \%$ \\
\hline Mean \pm SD & $21.5 \pm 2.67$ & \\
\hline \multicolumn{3}{|l|}{ Number of marriage } \\
\hline More than twice & 37 & $74 \%$ \\
\hline Twice & 8 & $16 \%$ \\
\hline Once & 5 & $10 \%$ \\
\hline \multicolumn{3}{|l|}{ Duration of current marriage } \\
\hline$<3$ years & 18 & $36 \%$ \\
\hline$\geq 3$ years & 32 & $64 \%$ \\
\hline Mean \pm SD & $5.2 \pm 4.42$ & \\
\hline Family characteristics & Frequency & Percent $\%$ \\
\hline \multicolumn{3}{|l|}{ Family residence } \\
\hline Rural & 31 & $62 \%$ \\
\hline Urban & 19 & $38 \%$ \\
\hline \multicolumn{3}{|l|}{ Family type } \\
\hline Extended family (live with parents) & 27 & $54 \%$ \\
\hline Nuclear (small family) & 23 & $46 \%$ \\
\hline \multicolumn{3}{|l|}{ Crowdedness rate } \\
\hline No crowdedness & 29 & $58 \%$ \\
\hline Crowded home $\quad>$ person/room & 21 & $42 \%$ \\
\hline \multicolumn{3}{|l|}{ Family income adequacy } \\
\hline Enough & 15 & $30 \%$ \\
\hline Not enough & 25 & $50 \%$ \\
\hline A little more than enough & 9 & $18 \%$ \\
\hline Enough and saving possible & 1 & $2 \%$ \\
\hline
\end{tabular}


Table 2. Distribution of the study sample according to life style and sexual pattern $(\mathrm{N}=50)$

\begin{tabular}{|c|c|c|}
\hline Variable & Frequency & Percent $\%$ \\
\hline \multicolumn{3}{|l|}{ Smoking status } \\
\hline Ever smoked & 0 & $0 \%$ \\
\hline Smoked & 50 & $100 \%$ \\
\hline \multicolumn{3}{|c|}{ Duration of smoking (yrs) } \\
\hline$<5$ years & 24 & $48 \%$ \\
\hline 5- years & 16 & $32 \%$ \\
\hline 10- years & 4 & $8 \%$ \\
\hline 15- years & 6 & $12 \%$ \\
\hline Mean $\pm \mathrm{SD}$ & $6.32 \pm 7.67$ & \\
\hline \multicolumn{3}{|c|}{ Weight (Body mass index (BMI)) } \\
\hline Normal weight & 40 & $80 \%$ \\
\hline Over weight & 10 & $20 \%$ \\
\hline \multicolumn{3}{|l|}{ Nutrition } \\
\hline Adequate & 8 & $16 \%$ \\
\hline Inadequate & 42 & $84 \%$ \\
\hline \multicolumn{3}{|c|}{ Sleeping pattern at night } \\
\hline Regular & 10 & $20 \%$ \\
\hline Irregular & 40 & $80 \%$ \\
\hline \multicolumn{3}{|c|}{ Number of intercourses per week } \\
\hline Not sexually active & 6 & $12 \%$ \\
\hline Not stated & 14 & $28 \%$ \\
\hline 1 & 24 & $48 \%$ \\
\hline $2-3$ & 4 & $8 \%$ \\
\hline$\geq 4$ & 2 & $4 \%$ \\
\hline
\end{tabular}


Table 3. Distribution of the study sample according to infertility history $(\mathrm{N}=50)$

\begin{tabular}{|c|c|c|}
\hline Variables & Frequency & Percent $\%$ \\
\hline \multicolumn{3}{|l|}{ Infertility causes } \\
\hline Sexual problems (erection and ejaculatory problems) & 7 & $14 \%$ \\
\hline Sperm antibodies & 1 & $2 \%$ \\
\hline Hormonal problems & 10 & $20 \%$ \\
\hline Blockage of sperm transport & 14 & $28 \%$ \\
\hline Sperm production problems & 18 & $36 \%$ \\
\hline \multicolumn{3}{|l|}{ Duration of infertility } \\
\hline$<5$ years & 1 & $2 \%$ \\
\hline 5- years & 8 & $16 \%$ \\
\hline 10- years & 14 & $28 \%$ \\
\hline 15- years & 27 & $54 \%$ \\
\hline Mean \pm SD & $13.7 \pm 4.12$ & \\
\hline \multicolumn{3}{|l|}{ Infertility type } \\
\hline Primary & 42 & $84 \%$ \\
\hline Secondary & 8 & $16 \%$ \\
\hline \multicolumn{3}{|l|}{ Gender of children in secondary infertility } \\
\hline Not applicable & 42 & $84 \%$ \\
\hline Girl $\quad(q)$ & 6 & $12 \%$ \\
\hline Boy $\quad\left(ठ^{\Uparrow}\right)$ & 2 & $4 \%$ \\
\hline \multicolumn{3}{|l|}{ Duration of treatment } \\
\hline$<5$ years & 5 & $10 \%$ \\
\hline$\geq 5$ years & 45 & $90 \%$ \\
\hline \multicolumn{3}{|l|}{ Type of treatment } \\
\hline ART & 10 & $20 \%$ \\
\hline Traditional TTT & 40 & $80 \%$ \\
\hline
\end{tabular}

Prevalence of levels of depression, anxiety and Tension

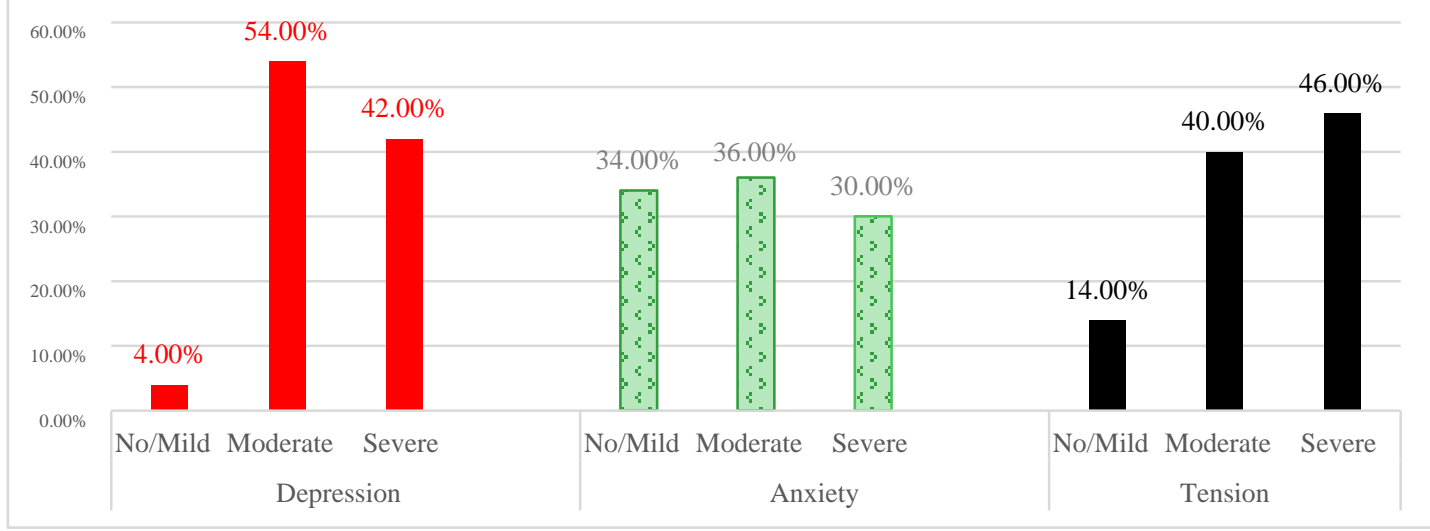

Figure 1. Prevalence of levels of depression, anxiety, and tension among studied infertile men 
Table 4. Relationship between socio-demographic and family characteristics and associated with psychological aspects

\begin{tabular}{|c|c|c|c|c|c|c|c|c|c|c|c|c|}
\hline \multirow[t]{2}{*}{ ariables } & \multicolumn{4}{|c|}{ Depression } & \multicolumn{4}{|c|}{ Anxiety } & \multicolumn{4}{|c|}{ Tension } \\
\hline & $\begin{array}{l}\text { No/ } \\
\text { mild }\end{array}$ & moderate & $\begin{array}{l}\text { Seve } \\
\text { re }\end{array}$ & $\begin{array}{l}\text { P- } \\
\text { Value }\end{array}$ & $\begin{array}{l}\text { No } \\
\text { /mild }\end{array}$ & $\begin{array}{l}\text { moder } \\
\text { ate }\end{array}$ & Severe & $\begin{array}{l}\text { P- } \\
\text { Value }\end{array}$ & $\begin{array}{l}\mathrm{No} / \\
\text { mild }\end{array}$ & $\begin{array}{l}\text { modera } \\
\text { te }\end{array}$ & Severe & $\begin{array}{l}\mathrm{P}- \\
\text { Value }\end{array}$ \\
\hline \multicolumn{13}{|c|}{ Socio demographic characteristics } \\
\hline \multicolumn{13}{|l|}{ Age } \\
\hline \multirow[t]{2}{*}{$<25$} & 0 & 7 & 3 & \multirow{8}{*}{0.000} & 4 & 4 & 2 & \multirow{8}{*}{0.619} & 2 & 3 & 5 & \multirow{8}{*}{0.000} \\
\hline & $0.0 \%$ & $26.0 \%$ & $14.3 \%$ & & $23.5 \%$ & $22.3 \%$ & $13.3 \%$ & & $28.6 \%$ & $15.0 \%$ & $21.7 \%$ & \\
\hline \multirow[t]{2}{*}{$25-$} & 0 & 2 & 3 & & 2 & 0 & 3 & & 0 & 3 & 2 & \\
\hline & $0.0 \%$ & $7.4 \%$ & $14.3 \%$ & & $11.8 \%$ & $0.0 \%$ & $20.0 \%$ & & $0.0 \%$ & $15.0 \%$ & $8.7 \%$ & \\
\hline \multirow[t]{2}{*}{$35-$} & 0 & 10 & 7 & & 5 & 8 & 4 & & 4 & 7 & 6 & \\
\hline & $0.0 \%$ & $37.0 \%$ & $33.3 \%$ & & $29.4 \%$ & $44.4 \%$ & $26.7 \%$ & & $57.1 \%$ & $35.0 \%$ & $26.1 \%$ & \\
\hline \multirow[t]{2}{*}{$45-$} & 2 & 8 & 8 & & 6 & 6 & 6 & & 1 & 7 & 10 & \\
\hline & $100 \%$ & $29.6 \%$ & $38.1 \%$ & & $35.3 \%$ & $33.3 \%$ & $40.0 \%$ & & $14.3 \%$ & $35.0 \%$ & $43.5 \%$ & \\
\hline \multicolumn{13}{|c|}{ Educational level } \\
\hline \multirow[t]{2}{*}{ Illiterate } & 0 & 7 & 2 & & 4 & 4 & 1 & & 0 & 6 & 3 & \\
\hline & $0.0 \%$ & $26.0 \%$ & $9.5 \%$ & & $23.5 \%$ & $22.2 \%$ & $6.7 \%$ & & $0.0 \%$ & $30.0 \%$ & $13.0 \%$ & \\
\hline \multirow[t]{2}{*}{ Primary } & 0 & 4 & 5 & & 2 & 3 & 4 & & 0 & 5 & 4 & \\
\hline & $0.0 \%$ & $14.9 \%$ & $23.8 \%$ & 0000 & $11.8 \%$ & $16.7 \%$ & $26.7 \%$ & 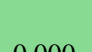 & $0.0 \%$ & $25.0 \%$ & $17.4 \%$ & م 000 \\
\hline \multirow[t]{2}{*}{ Secondary } & 2 & 11 & 11 & 0.000 & 9 & 8 & 7 & 0.000 & 5 & 8 & 11 & 0.000 \\
\hline & $100 \%$ & $40.7 \%$ & $52.4 \%$ & & $52.9 \%$ & $44.4 \%$ & $46.6 \%$ & & $71.4 \%$ & $40.0 \%$ & $47.9 \%$ & \\
\hline \multirow[t]{2}{*}{ University } & 0 & 5 & 3 & & 2 & 3 & 3 & & 2 & 1 & 5 & \\
\hline & $0.0 \%$ & $18.4 \%$ & $14.3 \%$ & & $11.8 \%$ & $16.7 \%$ & $20.0 \%$ & & $28.6 \%$ & $5.0 \%$ & $21.7 \%$ & \\
\hline \multicolumn{13}{|c|}{ Occupation type } \\
\hline \multirow[t]{2}{*}{ Craftsman } & 1 & 2 & 5 & \multirow{10}{*}{0.000} & 3 & 3 & 2 & & 2 & 2 & 4 & \\
\hline & $50.0 \%$ & $7.4 \%$ & $23.8 \%$ & & $17.7 \%$ & $16.7 \%$ & $13.3 \%$ & & $28.6 \%$ & $10.0 \%$ & $17.4 \%$ & \\
\hline \multirow[t]{2}{*}{ Employee } & 0 & 15 & 3 & & 7 & 8 & 3 & & 4 & 7 & 7 & \\
\hline & $0.0 \%$ & $55.6 \%$ & $14.3 \%$ & & $41.1 \%$ & $44.4 \%$ & $20.0 \%$ & & $57.1 \%$ & $35.0 \%$ & $30.4 \%$ & \\
\hline \multirow[t]{2}{*}{ Farmer } & 1 & 5 & 7 & & 4 & 3 & 6 & 0001 & 1 & 5 & 7 & 0000 \\
\hline & $50.0 \%$ & $18.5 \%$ & $33.3 \%$ & & $23.5 \%$ & $16.7 \%$ & $40.0 \%$ & 0.001 & $14.3 \%$ & $25.0 \%$ & $30.4 \%$ & 0.000 \\
\hline \multirow[t]{2}{*}{ Driver } & 0 & 5 & 5 & & 3 & 4 & 3 & & 0 & 6 & 4 & \\
\hline & $0.0 \%$ & $18.5 \%$ & $23.8 \%$ & & $17.7 \%$ & $22.2 \%$ & $20.0 \%$ & & $0.0 \%$ & $30.0 \%$ & $17.4 \%$ & \\
\hline Other job & 0 & 0 & 1 & & 0 & 0 & 1 & & 0 & 0 & 1 & \\
\hline & $0.0 \%$ & $0.0 \%$ & $4.8 \%$ & & $0.0 \%$ & $0.0 \%$ & $6.7 \%$ & & $0.0 \%$ & $0.0 \%$ & $4.4 \%$ & \\
\hline Marital & & & & & & & & & & & & \\
\hline Single & 0 & 4 & 0 & & 3 & 0 & 1 & & 0 & 0 & 4 & \\
\hline & $0.0 \%$ & $14.8 \%$ & $0.0 \%$ & & $17.6 \%$ & $0.0 \%$ & $6.6 \%$ & & $0.0 \%$ & $0.0 \%$ & $17.4 \%$ & \\
\hline Married & 0 & 4 & 8 & 0.011 & 2 & 6 & 4 & 0.000 & 0 & 4 & 8 & 0.002 \\
\hline & $0.0 \%$ & $14.8 \%$ & $38.1 \%$ & & $11.8 \%$ & $33.3 \%$ & $26.7 \%$ & & $0.0 \%$ & $20.0 \%$ & $34.8 \%$ & \\
\hline Divorced & 2 & 8 & 6 & & 7 & 7 & 2 & & 0 & 10 & 6 & \\
\hline
\end{tabular}




\begin{tabular}{|c|c|c|c|c|c|c|c|c|c|c|c|c|}
\hline & 100.0 & $29.6 \%$ & $28.6 \%$ & & $41.2 \%$ & $38.9 \%$ & $13.3 \%$ & & $0.0 \%$ & $50.0 \%$ & $26.1 \%$ & \\
\hline & $\%$ & & & & & & & & & & & \\
\hline \multirow[t]{2}{*}{ Separated } & 0 & 5 & 3 & & 3 & 1 & 4 & & 0 & 5 & 3 & \\
\hline & $0.0 \%$ & $18.5 \%$ & $14.3 \%$ & & $17.6 \%$ & $5.6 \%$ & $26.7 \%$ & & $0.0 \%$ & $25.0 \%$ & $13.0 \%$ & \\
\hline \multirow[t]{2}{*}{ Cohabiting } & 0 & 6 & 4 & & 2 & 4 & 4 & & 7 & 1 & 2 & \\
\hline & $0.0 \%$ & $22.3 \%$ & $19.0 \%$ & & $11.8 \%$ & $22.2 \%$ & $26.7 \%$ & & $100 \%$ & $5.0 \%$ & $8.7 \%$ & \\
\hline \multicolumn{13}{|c|}{ Age at $1^{\text {st }}$ marriage } \\
\hline \multirow[t]{2}{*}{$<20$ years } & 1 & 14 & 7 & \multirow{4}{*}{0.000} & 6 & 7 & 9 & \multirow{4}{*}{$\begin{array}{l}0.012 \\
8\end{array}$} & 1 & 13 & 8 & \multirow{4}{*}{0.000} \\
\hline & $50.0 \%$ & $51.9 \%$ & $33.3 \%$ & & $35.3 \%$ & $38.9 \%$ & $60.0 \%$ & & $14.3 \%$ & $65.0 \%$ & $34.8 \%$ & \\
\hline \multirow[t]{2}{*}{ 20- years } & 1 & 13 & 14 & & 11 & 11 & 6 & & 6 & 7 & 15 & \\
\hline & $50.0 \%$ & $48.1 \%$ & $66.7 \%$ & & $64.7 \%$ & $61.1 \%$ & $40.0 \%$ & & $85.7 \%$ & $35.0 \%$ & $65.2 \%$ & \\
\hline \multicolumn{13}{|c|}{ Number of marriage } \\
\hline \multirow{2}{*}{$\begin{array}{l}\text { More } \\
\text { twice }\end{array}$} & 2 & 22 & 13 & \multirow{6}{*}{0.000} & 15 & 13 & 9 & \multirow{6}{*}{0.000} & 7 & 15 & 15 & \multirow{6}{*}{0.000} \\
\hline & $100 \%$ & $81.5 \%$ & $61.9 \%$ & & $88.2 \%$ & $72.2 \%$ & $60.0 \%$ & & $100 \%$ & $75.0 \%$ & $65.2 \%$ & \\
\hline \multirow[t]{2}{*}{ Twice } & 0 & 3 & 5 & & 1 & 3 & 4 & & 0 & 3 & 5 & \\
\hline & $0.0 \%$ & $11.1 \%$ & $23.8 \%$ & & $5.9 \%$ & $16.7 \%$ & $26.7 \%$ & & $0.0 \%$ & $15.0 \%$ & $21.8 \%$ & \\
\hline \multirow[t]{2}{*}{ One } & 0 & 2 & 3 & & 1 & 2 & 2 & & 0 & 2 & 3 & \\
\hline & $0.0 \%$ & $7.4 \%$ & $14.3 \%$ & & $5.9 \%$ & $11.1 \%$ & $13.3 \%$ & & $0.0 \%$ & $10.0 \%$ & $13.0 \%$ & \\
\hline \multicolumn{13}{|c|}{ Duration of current marriage } \\
\hline \multirow[t]{2}{*}{$<3$ years } & 0 & 11 & 7 & \multirow{4}{*}{0.017} & 3 & 10 & 5 & \multirow{4}{*}{0.001} & 1 & 8 & 9 & \multirow{4}{*}{0.001} \\
\hline & $0.0 \%$ & $40.7 \%$ & $33.3 \%$ & & $17.6 \%$ & $55.6 \%$ & $33.3 \%$ & & $14.3 \%$ & $40.0 \%$ & $39.1 \%$ & \\
\hline \multirow[t]{2}{*}{$\geq 3$ years } & 2 & 16 & 14 & & 14 & 8 & 10 & & 6 & 12 & 14 & \\
\hline & $100 \%$ & $59.3 \%$ & $66.7 \%$ & & $82.4 \%$ & $44.4 \%$ & $66.7 \%$ & & $85.7 \%$ & $60.0 \%$ & $60.9 \%$ & \\
\hline \multicolumn{13}{|c|}{ Family characteristics } \\
\hline \multicolumn{13}{|c|}{ Family residence } \\
\hline Rural & 1 & 17 & 13 & & 9 & 10 & 12 & & 4 & 13 & 14 & \\
\hline & $50.0 \%$ & $63.0 \%$ & $61.9 \%$ & $0<0$ & $52.9 \%$ & $55.6 \%$ & $80.0 \%$ & 000 & $57.1 \%$ & $65.0 \%$ & $60.9 \%$ & 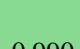 \\
\hline Urban & 1 & 10 & 8 & (1.07 & 8 & 8 & 3 & 0.001 & 3 & 7 & 9 & 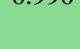 \\
\hline & $50.0 \%$ & $37.0 \%$ & $38.1 \%$ & & $47.1 \%$ & $44.4 \%$ & $20.0 \%$ & & $42.9 \%$ & $35.0 \%$ & $39.1 \%$ & \\
\hline Family type & & & & & & & & & & & & \\
\hline Extended & 1 & 13 & 13 & & 8 & 9 & 10 & & 4 & 10 & 13 & \\
\hline & $50.0 \%$ & $48.1 \%$ & $61.9 \%$ & 0006 & $47.1 \%$ & $50.0 \%$ & $66.7 \%$ & 0005 & $57.1 \%$ & $50.0 \%$ & $56.5 \%$ & 0600 \\
\hline Nuclear & 1 & 14 & 8 & 0.000 & 9 & 9 & 5 & 0.005 & 3 & 10 & 10 & 0.000 \\
\hline & $50.0 \%$ & $51.9 \%$ & $38.1 \%$ & & $52.9 \%$ & $50.0 \%$ & $33.3 \%$ & & $42.9 \%$ & $50.0 \%$ & $43.5 \%$ & \\
\hline Crowdednes & rate & & & & & & & & & & & \\
\hline No & 2 & 15 & 12 & & 9 & 13 & 7 & & 3 & 10 & 16 & \\
\hline & $100 \%$ & $55.6 \%$ & $57.1 \%$ & 0.349 & $52.9 \%$ & $72.2 \%$ & $46.7 \%$ & 0.720 & $42.9 \%$ & $50.0 \%$ & $69.6 \%$ & 0.000 \\
\hline Crowded home & 0 & 12 & 9 & & 8 & 5 & 8 & & 4 & 10 & 7 & \\
\hline & $0.0 \%$ & $44.5 \%$ & $42.9 \%$ & & $47.1 \%$ & $27.8 \%$ & $53.3 \%$ & & $57.1 \%$ & $50.0 \%$ & $30.4 \%$ & \\
\hline Family incor & e adec & acy & & & & & & & & & & \\
\hline
\end{tabular}




\begin{tabular}{|c|c|c|c|c|c|c|c|c|c|c|c|c|}
\hline Enough & 1 & 6 & 8 & & 4 & 5 & 6 & & 0 & 5 & 10 & \\
\hline & $50.0 \%$ & $22.2 \%$ & $38.1 \%$ & & $23.5 \%$ & $27.8 \%$ & $40.0 \%$ & & $0.0 \%$ & $25.0 \%$ & $43.5 \%$ & \\
\hline \multirow[t]{2}{*}{ Not enough } & 1 & 15 & 9 & & 8 & 9 & 8 & & 3 & 11 & 11 & \\
\hline & $50.0 \%$ & $55.6 \%$ & $42.9 \%$ & & $47.1 \%$ & $50.0 \%$ & $53.3 \%$ & & $42.9 \%$ & $55.0 \%$ & $47.9 \%$ & \\
\hline \multirow{2}{*}{$\begin{array}{l}\text { A little more } \\
\text { than enough }\end{array}$} & 0 & 6 & 3 & 0.000 & 4 & 4 & 1 & 0.000 & 4 & 4 & 1 & 0.000 \\
\hline & $0.0 \%$ & $22.2 \%$ & $14.2 \%$ & & $23.5 \%$ & $22.2 \%$ & $6.7 \%$ & & $57.1 \%$ & $20.0 \%$ & $4.3 \%$ & \\
\hline \multirow[t]{2}{*}{ Enough/saving } & 0 & 0 & 1 & & 1 & 0 & 0 & & 0 & 0 & 1 & \\
\hline & $0.0 \%$ & $0.0 \%$ & $4.8 \%$ & & $5.9 \%$ & $0.0 \%$ & $0.0 \%$ & & $0.0 \%$ & $0.0 \%$ & $4.3 \%$ & \\
\hline
\end{tabular}

Table 5. Relationship between sample according to life style and sexual pattern and associated with psychological aspects $(\mathrm{N}=50)$

\begin{tabular}{|c|c|c|c|c|c|c|c|c|c|c|c|c|}
\hline \multirow[t]{2}{*}{ Variables } & \multicolumn{4}{|c|}{ Depression } & \multicolumn{4}{|c|}{ Anxiety } & \multicolumn{4}{|c|}{ Tension } \\
\hline & $\begin{array}{l}\mathrm{No} / \\
\text { mild }\end{array}$ & $\begin{array}{c}\text { moder } \\
\text { ate }\end{array}$ & $\begin{array}{c}\text { Sever } \\
\mathrm{e}\end{array}$ & $\begin{array}{c}\text { P- } \\
\text { Value }\end{array}$ & $\begin{array}{l}\mathrm{No} / \\
\text { mild }\end{array}$ & $\begin{array}{c}\text { modera } \\
\text { te }\end{array}$ & Severe & $\begin{array}{c}\mathrm{P}- \\
\text { Value }\end{array}$ & $\begin{array}{l}\mathrm{No} / \\
\text { mild }\end{array}$ & moderate & Severe & $\begin{array}{c}\text { P- } \\
\text { Value }\end{array}$ \\
\hline \multicolumn{13}{|c|}{ Duration of smoking (yrs) } \\
\hline \multirow[t]{2}{*}{$<5$ years } & 1 & 12 & 11 & \multirow{8}{*}{0.224} & 8 & 7 & 9 & \multirow{8}{*}{0.000} & 2 & 10 & 12 & \multirow{8}{*}{0.005} \\
\hline & $50.0 \%$ & $44.5 \%$ & $52.4 \%$ & & $47.1 \%$ & $38.9 \%$ & $60.1 \%$ & & $28.6 \%$ & $50.0 \%$ & $52.2 \%$ & \\
\hline \multirow[t]{2}{*}{ 5- years } & 1 & 9 & 6 & & 7 & 7 & 2 & & 2 & 6 & 8 & \\
\hline & $50.0 \%$ & $33.3 \%$ & $28.5 \%$ & & $41.1 \%$ & $38.9 \%$ & $13.3 \%$ & & $28.6 \%$ & $30.0 \%$ & $34.8 \%$ & \\
\hline \multirow[t]{2}{*}{ 10- years } & 0 & 3 & 1 & & 1 & 1 & 2 & & 1 & 2 & 1 & \\
\hline & $0.0 \%$ & $11.1 \%$ & $4.8 \%$ & & $5.9 \%$ & $5.5 \%$ & $13.3 \%$ & & $14.2 \%$ & $10.0 \%$ & $4.3 \%$ & \\
\hline \multirow[t]{2}{*}{15 - years } & 0 & 3 & 3 & & 1 & 3 & 2 & & 2 & 2 & 2 & \\
\hline & $0.0 \%$ & $11.1 \%$ & $14.3 \%$ & & $5.9 \%$ & $16.7 \%$ & $13.3 \%$ & & $28.6 \%$ & $10.0 \%$ & $8.7 \%$ & \\
\hline \multicolumn{13}{|c|}{ Weight (Body mass index (BMI)) } \\
\hline \multirow[t]{2}{*}{ Normal weight } & 2 & 23 & 15 & \multirow{4}{*}{0.051} & 15 & 11 & 14 & \multirow{4}{*}{0.009} & 7 & 15 & 18 & \multirow{4}{*}{0.001} \\
\hline & $100.0 \%$ & $85.2 \%$ & $71.4 \%$ & & $88.2 \%$ & $61.1 \%$ & $93.3 \%$ & & $100.0 \%$ & $75.0 \%$ & $78.3 \%$ & \\
\hline \multirow[t]{2}{*}{ Over weight } & 0 & 4 & 6 & & 2 & 7 & 1 & & 0 & 5 & 5 & \\
\hline & $0.0 \%$ & $14.8 \%$ & $28.6 \%$ & & $11.8 \%$ & $38.9 \%$ & $6.7 \%$ & & $0.0 \%$ & $25.0 \%$ & $21.7 \%$ & \\
\hline \multicolumn{13}{|l|}{ Nutrition } \\
\hline \multirow[t]{2}{*}{ Adequate } & 0 & 5 & 3 & \multirow{4}{*}{0.165} & 2 & 4 & 2 & \multirow{4}{*}{0.330} & 0 & 4 & 4 & \multirow{4}{*}{0.002} \\
\hline & $0.0 \%$ & $18.5 \%$ & $14.3 \%$ & & $11.8 \%$ & $22.2 \%$ & $13.3 \%$ & & $0.0 \%$ & $20.0 \%$ & $17.4 \%$ & \\
\hline \multirow[t]{2}{*}{ Inadequate } & 2 & 22 & 18 & & 15 & 14 & 13 & & 7 & 16 & 19 & \\
\hline & $100.0 \%$ & $81.5 \%$ & $85.7 \%$ & & $88.2 \%$ & $77.8 \%$ & $86.7 \%$ & & $100.0 \%$ & $80.0 \%$ & $82.6 \%$ & \\
\hline Sleeping pattern a & t night & & & & & & & & & & & \\
\hline Regular & 0 & 6 & 4 & & 1 & 7 & 2 & & 1 & 5 & 4 & \\
\hline & $0.0 \%$ & $22.2 \%$ & $19.0 \%$ & $008 ?$ & $5.9 \%$ & $38.9 \%$ & $13.3 \%$ & 0.035 & $14.3 \%$ & $25.0 \%$ & $17.4 \%$ & 0117 \\
\hline Irregular & 2 & 21 & 17 & 0.002 & 16 & 11 & 13 & 0.035 & 6 & 15 & 19 & 0.111 \\
\hline & $100.0 \%$ & $77.8 \%$ & $81.0 \%$ & & $94.1 \%$ & $61.1 \%$ & $86.7 \%$ & & $85.7 \%$ & $75.0 \%$ & $82.6 \%$ & \\
\hline Number of interco & urses per & week & & & & & & & & & & \\
\hline Not sexually active & 0 & 3 & 3 & & 1 & 3 & 2 & & 1 & 2 & 3 & \\
\hline & $0.0 \%$ & $11.2 \%$ & $14.3 \%$ & & $5.9 \%$ & $16.7 \%$ & $13.3 \%$ & & $14.3 \%$ & $10.0 \%$ & $13.0 \%$ & \\
\hline Not stated & 0 & 12 & 2 & & 2 & 8 & 4 & & 0 & 11 & 3 & \\
\hline & $0.0 \%$ & $44.4 \%$ & $9.5 \%$ & & $11.8 \%$ & $44.4 \%$ & $26.7 \%$ & & $0.0 \%$ & $55.0 \%$ & $13.0 \%$ & \\
\hline 1 & 2 & 10 & 12 & 0081 & 11 & 7 & 6 & 0231 & 6 & 7 & 11 & 0.004 \\
\hline & $100.0 \%$ & $37.0 \%$ & $57.2 \%$ & 0.001 & $64.6 \%$ & $38.9 \%$ & $40.0 \%$ & 0.251 & $85.7 \%$ & $35.0 \%$ & $47.9 \%$ & \\
\hline $2-3$ & 0 & 0 & 4 & & 1 & 0 & 3 & & 0 & 0 & 4 & \\
\hline & $0.0 \%$ & $0.0 \%$ & $19.0 \%$ & & $5.9 \%$ & $0.0 \%$ & $20.0 \%$ & & $0.0 \%$ & $0.0 \%$ & $17.4 \%$ & \\
\hline$\geq 4$ & 0 & 2 & 0 & & 2 & 0 & 0 & & 0 & 0 & 2 & \\
\hline & $0.0 \%$ & $7.4 \%$ & $0.0 \%$ & & $11.8 \%$ & $0.0 \%$ & $0.0 \%$ & & $0.0 \%$ & $0.0 \%$ & $8.7 \%$ & \\
\hline
\end{tabular}


Table 6. Relationship between sample according to infertility history and associated with psychological aspects $(\mathrm{N}=50)$

\begin{tabular}{|c|c|c|c|c|c|c|c|c|c|c|c|c|}
\hline \multirow[t]{2}{*}{ Variables } & \multicolumn{4}{|c|}{ Depression } & \multicolumn{4}{|c|}{ Anxiety } & \multicolumn{4}{|c|}{ Tension } \\
\hline & $\begin{array}{l}\mathrm{No} / \\
\text { mild }\end{array}$ & $\begin{array}{c}\text { moder } \\
\text { ate }\end{array}$ & Severe & $\begin{array}{c}\text { P- } \\
\text { Value } \\
\end{array}$ & $\begin{array}{l}\mathrm{No} / \\
\text { mild }\end{array}$ & $\begin{array}{c}\text { moderat } \\
\mathrm{e}\end{array}$ & Severe & $\begin{array}{c}\mathrm{P}- \\
\text { Value }\end{array}$ & No/mild & $\begin{array}{c}\text { modera } \\
\text { te }\end{array}$ & Severe & $\begin{array}{c}\text { P- } \\
\text { Value } \\
\end{array}$ \\
\hline \multicolumn{13}{|l|}{ Infertility causes } \\
\hline \multirow[t]{2}{*}{$\begin{array}{l}\text { Erection/ejaculatory } \\
\text { problem }\end{array}$} & 0 & 4 & 3 & \multirow{10}{*}{0.000} & 3 & 2 & 2 & \multirow{10}{*}{0.007} & 1 & 4 & 2 & \multirow{10}{*}{0.000} \\
\hline & $0.0 \%$ & $14.9 \%$ & $14.3 \%$ & & $17.6 \%$ & $11.1 \%$ & $13.3 \%$ & & $14.3 \%$ & $20.0 \%$ & $8.7 \%$ & \\
\hline \multirow[t]{2}{*}{ Sperm antibodies } & 0 & 0 & 1 & & 0 & 1 & 0 & & 1 & 0 & 0 & \\
\hline & $0.0 \%$ & $0.0 \%$ & $4.8 \%$ & & $0.0 \%$ & $5.6 \%$ & $0.0 \%$ & & $14.3 \%$ & $0.0 \%$ & $0.0 \%$ & \\
\hline \multirow{2}{*}{$\begin{array}{l}\text { Hormonal } \\
\text { problems }\end{array}$} & 1 & 4 & 5 & & 1 & 7 & 2 & & 4 & 2 & 4 & \\
\hline & $50.0 \%$ & $14.8 \%$ & $23.8 \%$ & & $6.0 \%$ & $39.0 \%$ & $13.4 \%$ & & $57.2 \%$ & $100.0 \%$ & $17.4 \%$ & \\
\hline \multirow{2}{*}{$\begin{array}{c}\text { Blockage } \\
\text { transport }\end{array}$} & 1 & 8 & 5 & & 5 & 4 & 5 & & 1 & 7 & 6 & \\
\hline & $50.0 \%$ & $29.6 \%$ & $23.8 \%$ & & $29.4 \%$ & $22.1 \%$ & $33.3 \%$ & & $14.3 \%$ & $35.0 \%$ & $26.1 \%$ & \\
\hline \multirow{2}{*}{$\begin{array}{l}\text { Sperm production } \\
\text { problems }\end{array}$} & 0 & 11 & 7 & & 8 & 4 & 6 & & 0 & 7 & 11 & \\
\hline & $50.0 \%$ & $40.7 \%$ & $25.9 \%$ & & $47.0 \%$ & $22.2 \%$ & $40.0 \%$ & & $0.0 \%$ & $35.0 \%$ & $47.8 \%$ & \\
\hline \multicolumn{13}{|l|}{ Duration of infertility } \\
\hline \multirow[t]{2}{*}{$<5$ years } & 0 & 0 & 1 & \multirow{8}{*}{0.096} & 0 & 1 & 0 & \multirow{8}{*}{0.011} & 0 & 0 & 1 & \multirow{8}{*}{0.001} \\
\hline & $0.0 \%$ & $0.0 \%$ & $4.8 \%$ & & $0.0 \%$ & $5.6 \%$ & $0.0 \%$ & & $0.0 \%$ & $0.0 \%$ & $4.4 \%$ & \\
\hline \multirow[t]{2}{*}{ 5- years } & 0 & 4 & 4 & & 2 & 3 & 3 & & 0 & 4 & 4 & \\
\hline & $0.0 \%$ & 14.8 & $19.1 \%$ & & $11.8 \%$ & $16.7 \%$ & $20.0 \%$ & & $0.0 \%$ & $20.0 \%$ & $17.4 \%$ & \\
\hline \multirow[t]{2}{*}{ 10- years } & 0 & 8 & 6 & & 5 & 5 & 4 & & 3 & 6 & 5 & \\
\hline & $0.0 \%$ & $29.6 \%$ & $28.5 \%$ & & $29.4 \%$ & $27.7 \%$ & $26.7 \%$ & & $42.9 \%$ & $30.0 \%$ & $21.7 \%$ & \\
\hline \multirow[t]{2}{*}{ 15- years } & 2 & 15 & 10 & & 10 & 9 & 8 & & 4 & 10 & 13 & \\
\hline & $100.0 \%$ & $55.6 \%$ & $47.6 \%$ & & $58.8 \%$ & $50.0 \%$ & $53.3 \%$ & & $57.1 \%$ & $50.0 \%$ & $56.5 \%$ & \\
\hline \multicolumn{13}{|l|}{ Infertility type } \\
\hline Secondary & 0 & 5 & 3 & & 1 & 5 & 2 & & 1 & 4 & 3 & \\
\hline & $0.0 \%$ & $18.5 \%$ & $14.3 \%$ & 0054 & $5.9 \%$ & $27.8 \%$ & $13.3 \%$ & 0051 & $14.3 \%$ & $20.0 \%$ & $13.0 \%$ & 0038 \\
\hline Primary & 2 & 22 & 18 & 0.034 & 16 & 13 & 13 & ו וסט & 6 & 16 & 20 & 0.030 \\
\hline & $100.0 \%$ & $81.5 \%$ & $85.7 \%$ & & $94.1 \%$ & $72.2 \%$ & $86.7 \%$ & & $85.7 \%$ & $80.0 \%$ & $87.0 \%$ & \\
\hline Gender of children $\mathrm{i}$ & in second: & Iry infert & ility & & & & & & & & & \\
\hline Girl $\quad(P)$ & 0 & 1 & 5 & & 0 & 5 & 1 & & 4 & 1 & 1 & \\
\hline & $0.0 \%$ & $3.7 \%$ & $23.8 \%$ & 0.031 & $0.0 \%$ & $27.8 \%$ & $6.7 \%$ & 0.242 & $57.1 \%$ & $5.0 \%$ & $4.3 \%$ & 0.001 \\
\hline Boy $\left(0^{7}\right)$ & 0 & 1 & 1 & ה & 1 & 0 & 1 & $0.2+2$ & 0 & 1 & 1 & 0.001 \\
\hline & $0.0 \%$ & $3.7 \%$ & $4.8 \%$ & & $5.9 \%$ & $0.0 \%$ & $6.7 \%$ & & $0.0 \%$ & $5.0 \%$ & $4.3 \%$ & \\
\hline Duration of TTT & & & & & & & & & & & & \\
\hline$<5$ years & 0 & 2 & 3 & & 1 & 2 & 2 & & 0 & 2 & 3 & \\
\hline & $0.0 \%$ & $7.4 \%$ & $14.3 \%$ & 0000 & $5.9 \%$ & $11.1 \%$ & $13.3 \%$ & 0000 & $0.0 \%$ & $90.0 \%$ & $13.0 \%$ & 0.000 \\
\hline$\geq 5$ years & 2 & 25 & 18 & 0.000 & 16 & 16 & 13 & 0.000 & 7 & 18 & 20 & 0.000 \\
\hline & $100.0 \%$ & $92.6 \%$ & $85.7 \%$ & & $94.1 \%$ & $88.9 \%$ & $86.7 \%$ & & $100.0 \%$ & $10.0 \%$ & $87.0 \%$ & \\
\hline Type of TTT & & & & & & & & & & & & \\
\hline ART & 0 & 5 & 5 & & 2 & 4 & 4 & & 0 & 4 & 6 & \\
\hline & $0.0 \%$ & $18.5 \%$ & $23.8 \%$ & 0.581 & $11.8 \%$ & $22.2 \%$ & $26.7 \%$ & 0.000 & $0.0 \%$ & $20.0 \%$ & $26.1 \%$ & 0.000 \\
\hline Traditional TTT & 2 & 22 & 16 & 0.001 & 15 & 14 & 11 & 0.000 & 7 & 16 & 17 & 0.000 \\
\hline & $100.0 \%$ & $81.5 \%$ & $76.2 \%$ & & $88.2 \%$ & $77.8 \%$ & $73.3 \%$ & & $100.0 \%$ & $80.0 \%$ & $73.9 \%$ & \\
\hline
\end{tabular}




\section{Discussion}

Infertility, although not a life-threatening illness, is a life crisis that leads to medical/ psychological/social/ethical issues. ${ }^{[55]}$ Infertility is a medical-related problem which can influence all the dimensions of one's individual and social life and can expose him to psycho-physical, socio-economic, sexual and family challenges. ${ }^{[29,56]}$ The inability to have children is a personal tragedy for millions of couples around the world. For a significant proportion of them, the private agony is compounded by a social stigma, which may have serious, long-run and far-reaching consequences. ${ }^{[57]}$ Infertility that affects almost entire society is a crisis with cultural, religious, and class-related aspects, which coexist with medical, psychiatric, psychological and social problems. Various studies, also, proved that infertility sometimes is accompanied by existential crises and emotional tensions such as lack of self-esteem, sense of bereavement, threat, depression and unconscious guilt feeling, high levels of anxiety, frustration, grief, emotional pressures, some sexual problems, interpersonal problems, suppressed anger, unsatisfactory-interpersonal-relationship, loss of control, inferiority and rejected feeling. ${ }^{[6,12,40,55]}$

Infertility as a global public-health-issue is a low-control-stressor often leading to an increased level of anxiety and depression. ${ }^{[42]}$ Infertility has been reported as an important stressor and life crisis in different cultural settings. When the couples discover that they may not be capable of having children, it is stressful, unexpected, and often a life-changing experience. Finding a solution to the fertility problem is often difficult, timeconsuming, and expensive as well. ${ }^{[8]}$ There has been less research about the experiences of men than of women affected by infertility, which probably reflects a similar pattern to the more limited research about men and fatherhood than women and motherhood. However, there is now a body of evidence that elucidates some of the psychological issues of infertility for men. ${ }^{[32]}$

To date, it is known that although infertility is not a direct cause of mortality in men; it is a significant cause of severe socio-psychological morbidity. ${ }^{[22]}$ Mishra and Singh stated that male infertility by itself doesn't threaten the life, but it has devastating psychosocial consequences on the infertile male because an infertile man is, generally, treated as an incomplete man. ${ }^{[9]}$ Ansbacher \& Ansbacher added that when an individual fails to meet his perceived perfection, feelings of inferiority or feeling less than others can surface. Because the goal is perfection, not creating a child can be perceived as a failure. These feelings of inferiority can dominate a person's life and the more an individual feels inferior, the more powerful the urge to conquer the goal will be. ${ }^{[33]}$

In the very-recent-studies, the main emotional disorders for different socio-economic milieu were shock, anxiety, depression, marital disharmony, anger, feelings of guilt, frustration, and sense of failure. The infertile ones had, in all mentioned factors, poor well-being; so they were susceptible to more physical and psychological stressors. Some studies reported that the psychological symptoms associated with infertility are equal to those related to cancer, hypertension, and cardiac rehabilitation. ${ }^{[1,3,12,26,28,33,40]}$ Gameiro \& Boivin mentioned that infertility is a crisis with many dimensions; mood (depression, anxiety), self-esteem, psychological adjustment, social adjustment, sexual adjustment, gender identity disturbances, marital adjustment, traits (extroversion, control), attributions and psychiatric symptoms. ${ }^{[27]}$ Infertile person is often exposed to psycho-physical/socio-economic/ sexual and family challenges. Low self-esteem and self-confidence, aimlessness, helplessness, and a negative self-image are the main consequences of infertility and its treatments. ${ }^{[56]}$

A man may be shocked when he find out himself infertile. There is still a common, but incorrect, belief that infertility is a woman's problem. Therefore, when a man is told that there is a sperm problem, he is often unprepared. Being told that there is a sperm problem can affect a man's sense of masculinity, sexuality, and potency. Most infertile men at some time struggle with the idea that they aren't able to do what other men can. ${ }^{[15]}$ In our culture, infertility considers as a reason for a divorce and/or multiple marriages. An infertile male is described as a functionless man in Upper Egypt. ${ }^{[25]}$ Although the psychological aspects of infertility/ childlessness and its treatment have been comprehensively investigated in women, the psychosocial consequences of infertility for men are less well understood. ${ }^{[32]}$ Unfortunately, no national study was found to assess psychological status among infertile Upper Egyptian men. So, the main purpose of the current study was to evaluate the existing and concerning the psychosocial aspects of male-related infertility and explore the implications of socio-demographic and lifestyle correlates in a sample of Upper Egyptian infertile men.

A series of studies showed that infertile men may develop feelings of hopelessness, anger, shame, and guilt in facing their partners as well as their parents and relatives. But in case of the unknown cause of infertility frustration may occur, and this may increase if the two partners have a different attitude towards treatment; the latter may damage the relationship. They display lower rates of self-esteem, higher anxiety, and more somatic symptoms. ${ }^{[10,26]}$ Men face a traumatic nature terrible shock when the cause of male-factor infertility is identified. ${ }^{[26]}$ A Man who struggling with infertility will find himself faced with many challenges. These 
challenges he faces can cause undue chronic stress which in turn can lead to anxiety disorders as well as depression. It seems apparent that there is a direct effect on a person's mental health. ${ }^{[3]}$ Researchers assessed whether infertility-related-emotional-responses varied by sex-specific diagnoses found that, men with male factor infertility experienced more 'negative-emotional-responses' than men whose partners were infertile or who were in couples in which fertility difficulties were unexplained. ${ }^{[8,32]}$ They concluded that men's responses to infertility approximated those of women only when the infertility was attributable to a male-factor. Other researchers found that their participants had avoided disclosure or revelation of emotional distress to protect their own dignity and relationships and to prevent their partners from further suffering. This study concluded that this practice had impeded the development of a satisfying life without children. ${ }^{[32]}$

The reported prevalence of depression and anxiety in infertile men varies from $4.9 \%$ to $38.0 \%$ in different studies. ${ }^{[30]}$ Since and consistent with literature review there are few studies in such important aspect, particularly in Upper Egypt. The following findings provided adequate details, to answer the questions of the study. The results of the present study portrayed that more than half (54.0\%) of the studied subjects were having a moderate level of depression and $42.0 \%$ of them had a severe level. However, $36.0 \%$ had a moderate level of anxiety and $30.0 \%$ had a severe level. Moreover, $46.0 \%$ of the subject had a severe tension and $40.0 \%$ a moderate level. To sum up, infertility has many implications for the psychological state of infertile men. ${ }^{[26]}$ It is apparent from the study that depression/anxiety/tension is not necessarily part of the past history of infertile men but it is the result of infertility. The high percentage of severe level of all aspects of psychological issues may be attributed to that a great band $(84.0 \%)$ of the studied sample suffer from primary infertility and $54.0 \%$ of them had infertility duration more than 15 years. It was observed that the longer time of infertility, the higher intensity of all psychological aspects (depression, anxiety, tension); with statistically significant in tension and anxiety $(\mathrm{P}=$ $0.001 \& 0.011$ ), respectively. This may be explained by Al-Asadi \& Hussein who reported that depression is thought to be a major public health problem associated with infertility, particularly in developing countries, where having a child is a very important and precious issue for sociocultural/economic, and religious reasons. ${ }^{[41]}$ This result is in accordance with Thompson's report which denoted that male factor infertility is proposed to have such a social stigma that it produces much negative social stress and a culture of secrecy and protectiveness. A man with male-factor-infertility reported a higher level of distress, increased anxiety and increased social isolation. It has also been suggested that men are so affected by male factor infertility; wives take the blame for the problem. ${ }^{[3]}$ Inability to conceive for a long-time after marriage, pressure from peers, partners/family and community, uncertainty of medical help, and physical/moral stress resulting from Assisted-ReproductiveTechniques (ART) could all influence the susceptibility of adult male to anxiety, as well as, depression and/or aggravate existing psychological symptoms. The negative impact of depression and anxiety on the couples' sexuality, marital happiness, and quality-of-life (QOL) may further the development of sexual dysfunction and the exacerbation of infertility. This interaction creates a vicious circle between depression/anxiety and infertile status and will undoubtedly worsen the situation, making male infertility a very difficult entity to be managed by andrologist, urologist, and medical psychologist in their daily clinical work. ${ }^{[30]}$ Ahmed and his colleagues reported that depression had a correlation with the duration after diagnosis of infertility was made and failed attempts at infertility treatment. ${ }^{[7]}$ Mohamed \& Gomaa added that anxiety levels are the highest in the second and third year of infertility and that these levels decrease after six years. However, this was not observed in the current study. ${ }^{[25]}$ Drosdzol \& Skrzypulec reported male infertility with a time-frame of 3 to 6 years causing the creation and severity of depressive symptoms. ${ }^{[58]}$

Additionally, it was clear that the type of infertility and gender of children in cases with secondary infertility affected the intensity of all psychological aspects (depression, anxiety, and tension). Primary infertility scored higher intensity of depression, anxiety, and tension; with statistically significant in all aspects $(\mathrm{P}=0.054,0.051$ $\&$ 0.038), respectively. The person who has had children suffered less from than ones with no children at all as the first ones did not deprive at all from children and parenthood fellings. These findings are consistent with Upkong ${ }^{[59]}$ as cited by Hassan, ${ }^{[12]}$ the non-fulfillment of a wish for a child is received as a stressful situation. It has been associated with emotional/psychological sequelae, including stress, tension, anxiety, and depression; male may experience stigma, sense of loss, \& diminished self-esteem in the setting of their infertility ${ }^{[12]}$ Severe depression and moderate anxiety were more prevalent among secondary infertile men with girl kids than boy ones $(\mathrm{P}=0.031 \& 0.242$, respectively). This may be attributed to that, the concept of conceiving and raising children are the usual and expected outcomes of their sexual relationship, and this may be in most Eastern, traditional and Arab societies, especially in rural areas, and particularly so in Upper Egypt; where the ability to procreate is seen as the essence of life. A male child doesn't only serve as a source of caregivers in old age but is also seen as a means of continuation of the lineage of a person and extending of the family name as well as for inheritance preservation. Parental and social pressures to perpetuate the family name can place a psychological 
burden on the infertile one. Infertile males are an object of ridicule among their peers in addition to the psychological burden they will face on a daily basis. This is in line with many authors. ${ }^{[1,32,35,36,37,38]}$

Etiology and causes of male-factor infertility play a crucial role in men's psychological status. Idiopathic infertility is the most recently being linked to higher levels of stress, anxiety, and depression. Researches show that sperm quality diminishes when men are faced with emotional distress. ${ }^{[3]}$ The results of the current study clearly presented the statistically significant differences between the causes of infertility and psychological status. Sperm production problems were scored the $1^{\text {st }}$ and the main etiological causes $(36.0 \%)$ which in-turn increase severity and intensity of depression $(25.9 \%)$, anxiety $(40.0 \%)$ and tension $(47.8 \%)$ than other mentioned etiological factors (sexual problems as erection and ejaculatory problems, sperm antibodies, hormonal problems, and blockage of sperm transport). This may be attributed to sperm production problems, in most cases, difficult to treat so the male can feel a blow to his masculinity. Our results are in accordance with a study in Slovenia, which denoted the link between psychological factors and semen quality was assessed, its result was $19.9 \%$ of these participants scored in the clinical range $\geq 34$, indicating that these men were possibly depressed. ${ }^{[32]}$ Other studies confirm a negative influence of increased stress on the semen volume, on the percentage of normal sperm shapes and on sperm concentration. Men become stressed due to infertility which can then increase issues with infertility. ${ }^{[3]}$

Most of the previously conducted studies indicated that the following factors are independently associated with anxiety/depressive disorder in infertile ones: age, sex, educational status, infertility duration, etiology of infertility, history/number of previous infertility treatment failures. ${ }^{[13,42]}$ The severity psychological distress, surly, affected by age of infertile male. As results revealed that older infertile men ( $\geq 45$ years) in our study sample had higher levels of depressive symptoms $(38.1 \%$ versus $14.3 \% ; \mathrm{P}=0.000)$, anxiety $(40.0 \%$ versus $13.3 \% ; \mathrm{P}=0.619)$ and tension (43.5\% versus $21.7 \% ; \mathrm{P}=0.000)$ than did younger men (<25 years). This was expected as by aging, the quality of men will be deteriorated. The findings of the Sultane's \& Tahir's study suggest that men aged 40-55 years reported more anxiety, and lower levels of self-esteem and sexual satisfaction as compared to men of other aged. ${ }^{[26]}$ It is supported by Jarow et al; they denoted that the time taken for a partner to become pregnant is longer when a man is middle-aged or older. Reasons for this may include a decrease in sexual activity, lower semen volume, changes to sperm motility (movement), a lower number of motile sperm, and possibly lower sperm function and DNA quality. ${ }^{[14]}$

The prediction that depression, anxiety, and tension will be more common among infertile men. Nodoutghly, marital status will affect infertile's psychological status. The results of the present study illustrated that severity of depression $(38.1 \%, \mathrm{P}=0.011)$, anxiety $(26.7 \%, \mathrm{P}=0.000)$, and tension $(34.8 \%, \mathrm{P}=0.002)$ was more prevalent among married men than others. This is may be explained by Thompson findings who stated, to those individuals, infertility may represent failure and it may feel like an insult to their sexuality. One can conclude that given their drive to succeed and their ability to achieve what they want, not being able to conceive a child would give them the feeling that they are unproductive and not capable. ${ }^{[3]}$ Men's fertility problems may also lead to stress-related conditions (erectile dysfunction, retrograde ejaculation, and premature) which can indirectly affect sexual pattern and its frequency. Additionally, the interpersonal relationship in marriage may also get impairment because of infertility. Feeling a psychological distance or withdrawal from one's partner is often observed in infertile couples. More than that, infertile men may also experience a decline/lack of sexual satisfaction such as arousal and orgasm. This could result in avoidance of sex altogether or having sex for the sole purpose of reproduction. Sex may become mechanical and unemotional as the couple tries to conceive. ${ }^{[26]}$ Through male factor infertility, feelings about fertility and sexual adequacy are interconnected for many men. ${ }^{\text {[24] }}$ Muller stated, "Sexual dissatisfaction of infertile men could also be related to a withdrawal from sexual activities. ${ }^{[60]}$ When an individual is facing decreased satisfaction within a life task, may very well be struggling with feelings of depression, anxiety, and stress. ${ }^{[3]}$

About $48.0 \%$ of the respondents had a history of marital discords; $32.0 \%$ resulting in divorce and $16.0 \%$ resulting in separated for no other reason than infertility, while $8.0 \%$ had no spouse at the time of the study. This is comparable to the observation made in other studies in Africa. The high rates of marital discord and divorce may be a factor responsible for the high rates of psychologic distress and its consequences in other situations in life. ${ }^{[34]}$ Joja and his colleagues documented that, it appears that emotional stress and marital difficulties are increased in couples where infertility lies with the man. ${ }^{[10]}$ The results of the current study revealed a presentable percentage of divorced infertile men exposed to sever level of; depression (28.6\%), anxiety (13.3\%), and tension (26.1\%). The identifiable risk factor of psychological distress among our respondents is the history of divorce from their spouses due to infertility. Men who are married but have never get a child with their wife are much more likely to be asked for divorce. Couples may choose divorce due to stress or based on the fact that they 
cannot imagine their life without children. ${ }^{[3]}$

Moreover, infertile men with longer duration of marriage ( $\geq 3$ years) had higher levels of depressive symptoms (66.7\% versus $33.3 \% ; \mathrm{P}=0.017)$, anxiety $(66.7 \%$ versus $33.3 \% ; \mathrm{P}=0.001)$ and tension $(60.9 \%$ versus $39.1 \%$; $\mathrm{P}$ $=0.001)$ than did with shorter duration of marriage $(<3$ years). This result is in line with Ahmed et al who reported that the prevalence of depression is directly proportional to the duration of married life; this was about $34.0 \%$ in males after the first four years of marriage and went up to $72.0 \%$ in the next two years. ${ }^{[7]}$

Regarding changes in infertile men's lifestyle; the results of the current study declare that the majority $(84.0 \% \&$ $80.0 \%$ ) of men reported a reduction in nutritional pattern and sleeping hours less than normal. This may be attributed to changes in psychological status of these men resulting from impairment of their fertility. Vice-versa severity of psychological symptoms was aggravated by changing men's lifestyle; severe depression, anxiety, and tension were more prevalent among ones who obtained inadequate nutrition $(85.7 \%, 86.7 \%, 82.6 \%)$ and inadequate and irregular sleeping hours $(81.0 \%, 86.7 \%, 82.6 \%)$, respectively.

Male-factor infertility may lead to psychological trauma, in which infertile man can't believe the event, in-turn leads to distress. This distress might have influenced the decision to join a new relation; this sentiment was linked with wishes to create a new life with a new wife, form a household and experience love. ${ }^{[32]}$ Our results revealed that around three-quarters $(74.0 \%)$ of the participants married more than twice, and $16.0 \%$ married twice. Moreover, all studied psychological aspects (depression, anxiety, and tension) were more intense with men who were multiple marriages (married more than twice), depression $(61.9 \%, \mathrm{P}=0.000)$, anxiety $(60.0 \%, \mathrm{P}$ $=0.000)$, and tension $(65.2 \%, \mathrm{P}=0.000)$. Yusufa et al declared in their study that the respondents of their study were predominantly young people that have been married for a variable length of time without a child of their own. The implications of this finding are quite numerous and of public health importance. Due to their young age, these men are likely to be sexually active with multiple partners, all in an effort to father a child. ${ }^{\text {[34] }}$

A range of men's psychosocial aspects may be influenced by infertility treatment. Psychosocial status may be affected by the type and duration of infertility treatment. The results of the present study revealed an association between psychological issues and type of treatment. Higher intensity of depression $(76.2 \%, \mathrm{P}=0.581)$, anxiety (73.3\%, $\mathrm{P}=0.000)$, and tension $(73.9 \%, \mathrm{P}=0.000)$ was observed among those whom used traditional treatment than those treated by assist reproductive therapy. This is contradicted with Donarelli et al who reported that a considerable literature has accumulated regarding the association of psychological distress with AssistedReproductive-Technology (ART) outcome, and several hypotheses have also been put forward to account for the reasons why psychosocial factors and an individual's level of distress could be associated with Assisted-Reproductive-Technology (ART) treatment outcome. ${ }^{[61]}$ Usage of traditional methods for infertility reflects educational, economic, and residency levels of the studied subject. It was clear that $18.0 \%$ of them were illiterate and $18.8 \%$ were only can read and write or had an elementary education, $62.0 \%$ were rural dwellers, $54.0 \%$ live in an extended family with their parents, $42.0 \%$ live in a crowded home and $50.0 \%$ did not have adequate family income. This may explain the usage of traditional treatment as infertile one will take his counseling and advises from his family (mother, mother-in-law, father, father-in-law).

The data of the current study were analyzed to see whether the infertile men having different educational qualifications differed in their psychological states. It was assumed that different educational qualifications would differentially contribute to the psychological concomitants of infertility. For the infertile man, the effect of education had a main significant $(\mathrm{P}=0.000)$. The findings of our study showed that men with university education had lower levels of depression, and anxiety as compared to those having elementary, matriculation or an intermediate education level. Results, further, showed a statistically significant association between educational qualification and psychological issues $(\mathrm{P}=0.000)$. Males with university education scored the least intensity of depression $(14.3 \%)$, and anxiety $(20.0 \%)$. This may be related to that low educated ones may be attributed to the etiology of their infertility to supernatural causes such as witchcraft, evil spirits, and God's retribution. Furthermore, Upper Egyptian men are still sticking to their old traditional and ancient pattern of life especially the inherited primitive prescriptions for treatment of infertility. Faith and traditional healers were the first treatment choice among illiterate men. This was in accordance with the findings of Ahmadi et al. who imply that a low level of education is one of the risk factors of psychological distress among their subjects. ${ }^{[34]}$

Another implication of infertility is the loss of productive time and money in search of a cure for infertility. ${ }^{\text {[10] }}$ The infertility treatment-cost can be enormous. In this study, 50.0\% of the respondents hadn't earned enough money which will not enable them to bear the cost of treatment. This problem is further complicated by the absence of a health-insurance policy to cover the care of infertility. ${ }^{[34]}$ This may be the answer to the question entitled why most $(80.0 \%)$ of the respondents' participants were patronizing alternative care providers' in 
addition to traditional care? It was not surprising to find that, severity of depression (42.9\%; $\mathrm{P}=0.000)$, anxiety $(53.3 \% ; \mathrm{P}=0.000)$, and tension $(47.9 \% ; \mathrm{p}=0.000)$ were more intense among poor men than rich ones. This may due to that, the patients belonging to poor families were concerned about themselves and about the treatment expenses because they were unable to bear high expenses of treatment of the threaded life medical disorder. ${ }^{[40]}$

Nodoughtly, residency, and type of family may affect infertile men's psychological status. The results of the current study revealed that the severity of 3 mentioned psychological aspects increased with rural, and extended family dwellers. Although previous studies found that family is considered the common sources of support included their own mothers and fathers, ${ }^{[32]}$ but our results aren't on the same line. In Upper Egypt, in the case of infertility, a family will be the main source of psychological stress as reproduction is considered a very crucial issue for preserve family name. Several studies, mostly from the Eastern countries, have declared that the reaction of relatives and families of the infertile couple have a major impact on the treatment-seeking behavior of infertility and on the development of depression and psychologic symptoms. ${ }^{[57]}$ This may be attributed to, in Islamic and eastern countries, childbearing is a very valuable issue; it considers a matter of life or death. Moreover, infertility is a main social onus for Upper Egyptian men, who are required to have children early in their marital life. Childlessness may result in social stigmatization of infertile person and may place him at a risk of serious social consequences. Men without kids often feel themselves as incomplete ones and this results in blame and pressure from their relatives, families, neighbors, and society, as well as a threat their marriage life; therefore, contributing to psychological problems. ${ }^{[12]}$ Additionally, the diagnosis of infertility causes many males to question their masculinity. ${ }^{[3,18,62]}$ In the context of cultural values, a married individual in general, and infertile one, in particular, are under severe social pressures to meet the expectations of performing traditional masculine roles particularly with reference to their ability to produce children. ${ }^{[26]}$ Globally, $10.0 \%$ agreed that fertility demonstrated through fatherhood reflected masculinity. ${ }^{[32]}$ Infertility related male-factor is, frequently, associated with a high level of stigma; as in a study conducted to explore the views of fertile ones towards infertile women versus men, Miall (1994) ${ }^{[62]}$ found that male infertility was, frequently, seen as arising from sexual dysfunction and thus associated with a higher levels of stigma. ${ }^{[63]}$ Many people assume that infertile men can't able to perform sexually. This stigma adds to the heightened insecurities in infertile men. Infertility related to male factor is proposed to has such a social stigma that it could produce stress, and a culture of secrecy/protectiveness to the extent that woman sometimes even take the blame for the couple's childlessness..,[64] However, infertile man is likely to be depressed, anxious, and may have lower masculinity and self-esteem scores. ${ }^{[65]}$

The psychologic distress related to infertility has been shown to increase over the course of treatment. Infertile ones can cycle through many different emotions since from the experience of trying to conceive naturally, after the diagnosis of infertility, prior/during/after treatments to the realization of not being able to have a child. In the current study, the results revealed exaggeration of the intensity for depression, anxiety, and tension by increasing treatment period ( $\geq 5$ years). A significant relationship was observed between duration of infertility treatment and intensity of depression, anxiety, and tension $(\mathrm{p}=0.000)$. A study which computed a depression scale comparing levels prior/during/after unsuccessful infertility treatment found that thirty-six percent $(36.0 \%)$ of the patients scored highly depressed prior to treatment and $44.0 \%$ scored highly depressed after the treatment. This study also compared depression levels to two different forms of treatment. An independent $\tau$-test revealed that the difference in pre $(\tau=0.09)$ and post $(\tau=1.40)$ scores for both studied groups wasn't statistically significant. ${ }^{[3]}$ Many studies have assessed the psychologic consequences which may be associated with infertility treatments varieties; some of them have found a correlation between distress, anxiety, and depression, and low ART treatment outcomes, however, a handful of studies hadn't reported such correlation. ${ }^{[13]}$ One study reported that infertile individual undergoing assisted conception (ART) appears to has an increased risk for psychopathological-distress, particularly, if the treatment failed; the general perception being that the last chance for the couple to have a biological child has also been wasted. ${ }^{[7,56]}$ Another study finding conducted by Fisher \& Hammarberg supported our findings. It reported that, In Poland, Men in the infertile couples had high levels of depressive symptoms and anxiety; however, in most cases, symptoms were mild to moderate. Couples with primary infertility, who had experienced at least three-years of fertility treatment, in Turkey, average anxiety related to treatment procedures increased among men. ${ }^{[32]}$

However, it should be noted that regardless of the cause of infertility, men usually are subject to more invasive interventions during the course of infertility treatment. A long-lasting infertility, as well as, a repeated experience of unsuccessful treatment are reported as to be important risk factors in predicting distress. Therefore, they may be prone to emotional responses, such as heightened anxiety or depression, due to invasiveness or adverse effects of the treatment. ${ }^{[8,28]}$ The physical, psychologic, and financial challenges associated with assisted reproductive 
techniques may have further impacts on the infertile one. ${ }^{[1]}$ Moreover, the period of infertility treatment, surely, may affect respondents' lifestyle, and sexual pattern which in-turn will affect psychological status. Long-lasting period of treatment will add an extra emotional, psychological, and financial burden. The results of our study revealed that a great majority of participants $(90.0 \%)$ spent more than 5 years for treatment. A significant association was found between duration of treatment and psychological aspects $(\mathrm{P}=0.000)$. Long-lasting time indicates more intensity of depression (85.7\%), anxiety (86.7\%), and tension (87.0\%). This may be attributed to that, the repeated procedures, such as sperm collection, might cause an increase in treatment-related anxiety in men. This may be attributed to the feeling of the useless of treatment which in-turn lead to loss of hope and frustration. Our results are supported by a study conducted to assessed psychological distress for infertile men, its results concluded that initiating treatment was associated with a decline in distress but only in men attending for $1^{\text {st }}$ consultation and not for those with longstanding difficulties. In a subsequent study in men who had repeat infertility assessment visits, those researchers found that distress increased during this time interval in men who had been undergoing prolonged treatment. ${ }^{[32]}$ In the same line, Tuzer et al reported, furthermore, that the depressive symptoms in men and heightened anxiety experienced during infertility treatment $(\mathrm{P}<0.01)$. Cost of the infertility treatment and the number of repeated procedures have also been reported as stress-related variables in the course of infertility. ${ }^{[8]}$

For men, the infertility treatment itself can become a stressful event. A male failing to achieve baby might experience feelings of frustration, disappointment and emotional upheaval, owing to prolonged efforts in terms of taking medication, treatment cost and treatment time. ${ }^{[33,46]}$ The current results illustrated that a presentable percentage either not sexually active $(12.0 \%)$ or refused $(28.0 \%)$ to report about their sexual pattern which indicated that it is not all right, around half of them (48.0\%) reported that they act intercourse only once per week. This may be attributed to those feelings of depression, anxiety, or stress in infertile men can cause psychogenic impotence, which heightens the feelings of inadequacy that already accompany infertility. The psychological stress related to infertility has been, in turn, affected sperm parameters in a significant/demonstrable way that may, further, affect erectile potency; infertility emotional-reactions may undermine or alter a previous consolidation of a sense of self as sexually adequate. Infertility weighs on many males' minds; this creates mental instability, which often results in impotence. ${ }^{[62]}$ Association was found between frequency of intercourse per week and psychological status, the high frequency of intercourse, the low intensity of depression, anxiety, and tension. However, this association is not significant in depression $(p=0.081)$, anxiety $(p=0.231)$. These results may be explained as sex is an instinctive part of human's life, and sexual function is a major determinant of overall health and general well-being. ${ }^{[66]}$ This finding also corroborates the findings of other authors who cited in and reported that infertility treatment results in anxiety and distress. Finally, they found that among infertile couples, who never suffered from any psychopathology within a period of four years, $12.0 \%$ of the studied subjects had an onset of a major depressive episode. ${ }^{[26]}$ Couples with long-lasting infertility, who have faced much unsuccessful treatment, reported a higher level of depression, low sex lives satisfaction, and a low level of well being. It is estimated that $40.0 \%$ of infertile individuals experience significant emotional distress with possible long-term implications. ${ }^{[64]}$ In Germany, current and pre-diagnosis recollections of intercourse frequency and sexual satisfaction were assessed in 68 consecutively recruited men with male-factor infertility. The frequency of intercourse was lower among those with relationships (and awareness of infertility) of longer duration. ${ }^{[32]}$

\section{Limitation of the Study}

The study has 4 main limitations that might have influenced the results we have reached. The $1^{\text {st }}$ one was that it is a cross-sectional study involving a small sample size. And doesn't allow us to establish causal inferences between study variables. The $2^{\text {nd }}$ one, the sample has been drawn only public hospital-based and not from many clinics and this may decrease the generalizability of study findings. The $3^{\text {rd }}$ one was the social stigma of being childless among infertile men is so severe in Upper Egypt, in turn, most of them refuse seeking counseling, however, some of them who asked for treatment, refused to participate in the study. So, the small sample size may have provided inadequate statistical power to detect some significant differences. The $4^{\text {th }}$ one was that many of our measures are self-reported. However, we used well-validated self-report instruments that have been found to be valid and reliable measures in a number of health surveys, using questionnaires and self-rating, although a useful for assessing the severity of symptoms, isn't the best way of identifying the existence of major depression as a disorder or differentiating between specific anxiety, and tension disorders. The study is further strengthened by the use of objective lab values obtained from physician's offices and lies in the methodology and instruments used for establishing the diagnosis of psychological distress. 


\section{Conclusion}

Based on the results of the current research, it would seem fair to conclude that Upper Egyptian men facing infertility could be struggling with psychological aspects. Such distortions could include depression, anxiety, and tension. For male, infertility becomes the focal point of daily discourse and tasks, often to the exclusion of other important aspects of life. Research results have indicated that there are established relationships among socio-demographic characteristics, lifestyle and sexual pattern and, tension, anxiety, and depression levels in those infertile men.

\section{Recommendation}

Based on the results of the study, the following recommendations can be derived:

1. As the study shed some light on the extent of psychological repercussions, which was negatively impacted on through the male infertility experience, thus the need for psychological assessment should be included in the assessment of male infertility. Infertility is associated with high levels of psychological morbidity. Our findings reinforce the need for andrologist, gynecologist, and infertility specialist and health care sectors as well as psychological professionals to look for psychosocial distress in males undergoing infertility treatment. In turn, infertile males should receive psychosocial support to get higher levels of coping skills and will be able to tolerate their situation better.

2. Stress management programs have been set up to reduce psychological distress which is a common part of the life of people struggling with infertility. Successful programs in dealing with infertility in Upper Egypt need to include the establishment of a community-based intervention strategy to educate people about infertility and give guidelines for proper treatment.

3. Infertility and assisted conception professionals and specialists should be, completely, aware of the values and importance of psychological issues in their customers, the need to make available, rapid, and, reliable screening for identifying ones at greater demand for psychological support, and the inclusion of supportive psychotherapy, and counseling in all general therapeutic framework of infertility.

4. Nurse as a counselor provides counseling, guidance, and have the responsibility to teach such techniques among infertile males with offering a great challenge in today's world. Mental health as well as Maternity/gynecologic health nurse should be fitted with the appropriate sciences, knowledge, and skills that were necessary to help people adjust to the daily problems \& related difficulties. Also, possible, we need additional \& continuous training for nurses who are employed in the fertility settings, to make them more aware of the psychological \& social domains and their impacts on clients.

5. In the light of limitations and across the wide implications of the present study, it is suggested that more research should be carried out with a larger sample from different provinces of Upper Egypt with respect to infertility and its psychological consequences.

6. Further research is needed to be conducted to understand the association between distress and fertility outcomes, as well as effective psychosocial interventions, particularly, exploring males' reactions and their coping in the context of the treatments.

\section{References}

[1] Verma, K., \& Baniya, G. (2016). A comparative study of depression among infertile and fertile women. International Journal of Research in Medical Sciences, 4(8), 3459-3465. https://doi.org/10.18203/ 2320-6012. ijrms20162312

[2] Inhorn, M., \& Patrizio, P. (2015). Infertility around the globe: new thinking on gender, reproductive technologies and global movements in the 21st century. Human Reproduction Update, 21(4), 411-426. https://doi.org/10.1093/humupd/dmv016

[3] Thompson, M. (2013). Infertility's Effect on Stress, Anxiety and Depression from an Adlerian Perspective. A thesis submitted to The Faculty of the Adler Graduate School.

[4] Parekattil, S., \& Agarwal, A. (2012). Male infertility: contemporary clinical approaches, andrology, ART \& antioxidants. springer science + business media, LLC. New York Heidelberg Dordrecht London, 307, 349-351. https://doi.org/10.1007/978-1-4614-3335-4

[5] Sinclair, S. (2000). Male infertility: nutritional and environmental considerations. Alternative Medicine Review, 5(1), 28-38.

[6] Galundia, R., \& Sethia, R. (2015). Infertility- An historical perspective. Home Science, 5(6), 701-702. 
[7] Ahmed, A., Fathima, N., Vishwakarma, S., Khan, A. P., Ramakrishna, S. R., \& Rozatti, R. (2014). Psychological evaluation of couples attending the infertility clinic in a tertiary care, teaching hospital. International Journal of Current Research Academic Review, 2(2), 133-147.

[8] Tuzer, V., Tuncel, A., Goka, S., Bulut, S., Yuksel, F., Atan, A., \& Goka, E. (2010). Marital adjustment and emotional symptoms in infertile couples: gender differences. Turkish Journal of Medical Sciences, 40(2), 229-237. https://doi.org/10.3906/sag-0901-17

[9] Mishra, R., Verma, H., Singh, N., \& Singh, S. (2012). Male infertility: lifestyle and oriental remedies. Journal of Scientific Research, 56, 93-101.

[10] Joja, O. D., Dinu, D., \& Paun, D. (2015). Psychological aspects of male infertility. An overview. Procedia Social and Behavioral Sciences, 187, 359-363. https://doi.org/10.1016/j.sbspro.2015.03.067

[11] Lewis, S. (2014). Male Infertility: fact sheet (pp. 1-3). Infertility Network UK.

[12] Hassan, H. (2016). Infertility profile, psychological ramifications and reproductive tract infection among infertile women, in northern Upper Egypt. Journal of Nursing Education and Practice, 6(4), 92-108. https://doi.org/10.5430/jnep.v6n4p92

[13] Karimzadeh, M., Salsabili, N., Asbagh, F., Teymouri, R., Golamreza, P. G., \& Naeini, T. (2017). Psychological disorders among iranian infertile couples undergoing assisted reproductive technology (ART). Iran J Public Health, 46(3), 333-341.

[14] McLachlan, R., Cook, R., de Kretser, D., Lording, D., Baker, H., \& Kovacs, G. (2014). Male Infertility: A child of our own (4th ed.), pp. 1-2, pp. 15-26, pp. 37-38, pp. 56-63, pp. 72-78. Australian Government Department of Health: Andrology Australia (The Australian Centre of Excellence in Male Reproductive Health). Retrieved from www.andrologyaustralia.org

[15] McLachlan, R. (2015). Male infertility: fact sheet. Andrology Australia: What Every Man Needs to Know (pp. 1-2).

[16] O' Brien, k., Varghese, A., \& Agarwal, A. (2010). The genetic causes of male factor infertility: A review. Fertility and Sterility, 93(1), 1-12. https://doi.org/10.1016/j.fertnstert. 2009.10.045

[17] American Society for Reproductive Medicine. (2015). Diagnostic evaluation of the infertile male: A committee opinion. Fertil and Sterility, 103(3), 18-25. https://doi.org/10.1016/j.fertnstert.2014.12.103

[18] Fisher, J., \& Hammarberg, K. (2017). Psychological Aspects of Infertility Among Men. Endocrinology of the Testis and Male Reproduction, Endocrinology (pp. 1-31). https://doi.org/10.1007/978-3-319-29456-8_46-1

[19] Agarwal, A., Virk, G., Ong, C., \& Plessis, S. (2014). Effect of oxidative stress on male reproduction. World J Mens Health, 32(1), 1-17. https://doi.org/10.5534/wjmh.2014.32.1.1

[20] Jungwirth, A., Diemer, T., Dohle, G. R., Giwercman, A., Kopa, Z., Krausz, C., \& Tournaye, H. (2012). Guidelines on male infertility. European Association of Urology, 6-8.

[21] Ghafel, H. (2017). Assessment of Occupational Hazards that Affecting Male Fertility in Baghdad City. IOSR Journal of Nursing and Health Science (IOSR-JNHS), 6(4), 77-83. https://doi.org/10.9790/1959-0604017783

[22] Okonofua, F. (2005). Female and male infertility in Nigeria. A thesis submitted to Department of Public Health Sciences: Division of International Health (IHCAR) Karolinska Institutet, Stockholm, Sweden.

[23] Marc, G. M., \& Schlegel, P. (2013). Surgical and Medical Management of Male Infertility. Cambridge University Press, pp.1-11.

[24] Keylor, R., \& Roberta, A. (2010). Male Infertility: Integrating an Old Psychoanalytic Story with the Research Literature. Studies in Gender and Sexuality, 11(2), 60-77. https://doi.org/10.1080/15240651003666326

[25] Mohamed, N., \& Gomaa, S. (2015). Study Level of Anxiety among infertile Egyptian and Sudanese women. European Journal of Academic Essays, 2(11), 60-65.

[26] Sultan, S., \& Tahir, A. (2011). Psychological consequences of infertility. Hellenic Journal of Psychology, 8, 229-247. 
[27] Gameiro, S., \& Boivin, J. (2013, July 3-5). History of Psychology in Infertility Medicine: Infertility in History, Science and Culture. Cardiff Fertility Studies Research Group. University of Edinburgh. Retrieved from http://psych.cf.ac.uk/fertilitystudies/

[28] Masoumi, S., Poorolajal, J., Keramat, A., \& Moosavi, S. (2013). Prevalence of depression among infertile couples in Iran: A Meta-Analysis Study. Iranian J Publ Health, 42(5), 458-466.

[29] Smith, J., Walsh, T., Shindel, A., Turek, P., Wing, H., Pasch, L., \& Katz, P. (2009). Sexual, marital, and social impact of a man's perceived infertility diagnosis. J Sex Med, 6(9), 2505-2515. https://doi.org/10.1111/j.1743-6109.2009.01383.x

[30] Yang, B., Zhang, J., Qi, Y., Wang, P., Jiang, R., \& Li, H. (2017). Assessment on occurrences of depression and anxiety and associated risk factors in the infertile Chinese men. American Journal of Men's Health, 1-8. https://doi.org/10.1177/1557988317695901

[31] Domar, A., Moragianni, V., Ryley, D., \& Urato, A. (2013). The risks of selective serotonin reuptake inhibitor use in infertile women: a review of the impact on fertility, pregnancy, neonatal health and beyond. Human Reproduction, 28(1). https://doi.org/10.1093/humrep/des383

[32] Fisher, J., \& Hammarberg, K. (2012). Psychological and social aspects of infertility in men: an overview of the evidence and implications for psychologically informed clinical care and future research. Asian Journal of Andrology, 14, 121-129. https://doi.org/10.1038/aja.2011.72

[33] Tovliat, V., Motaghedifard, M., \& Tamannaeifar, M. (2015). A Comparison of Stress Reactions, Coping Styles, Subjective Well-Being and Its Sub-Scales in Fertile and Infertile Women. Journal of Advanced Medical Sciences and Applied Technologies (JAMSAT), 1(2), 93-97.

[34] Yusufa, A., Maitamab, H., Amedua, M., Ahmedb, M., \& Mbibub, H. (2012). Socio-demographic correlates of psychological distress among male patients with infertility in Zaria, Nigeria. African Journal of Urology, 18, 170-174. https://doi.org/10.1016/j.afju.2012.08.009

[35] Dyer, S. J., Abraham, N., Makeno, N. E., \& van der Spuy, Z. M. (2004). You are a man because you have children: experiences of reproductive health knowledge and treatment seeking behavior among couples with infertility in South Africa. Human Reproduction, 19, 960-967. https://doi.org/10.1093/humrep/deh195

[36] Gerritis, T. (1997). Social and cultural aspect of infertility in Mozambique. Patient Education and Counseling, 31, 38-39. https://doi.org/10.1016/S0738-3991(97)01018-5

[37] Horbst, V. (2010). Male perspective on infertility and assisted reproductive technologies (ART) in Sub-Saharan African context. FV\&V in $O B G Y N, 22-27$.

[38] Umezulike, A. C., \& Efetie, E. R. (2004). The psychological trauma of infertility in Nigeria. International Journal of Gynaecology and Obstetrics, 84, 178-180. https://doi.org/10.1016/S0020-7292(03)00316-3

[39] Ahmadi, H., Montaser-Kouhsari, L., Nowroozi, M., \& Bazargan-Hejazi, S. (2011). Male infertility and depression: A neglected problem in the Middle East. J Sex Med, 8(3), 824-830. https://doi.org/10.1111/j.1743-6109.2010.02155.x

[40] Soltani, M., Shairi, M. R., Roshan, R., \& Rahimi, Ch. (2014). The impact of emotionally focused therapy on emotional distress in infertile couples. Int J Fertil Steril, 7(4), 337-344.

[41] Al-Asadi, J., \& Hussein, Z. (2015). Depression among infertile women in Basrah, Iraq: Prevalence and risk factors. Journal of the Chinese Medical Association, 78, 673-677. https://doi.org/10.1016/j.jcma.2015.07.009

[42] Maroufizadeh, S., Ghaheri, A., Almasi-Hashiani, A., Mohammadi, M., Navid, B., Ezabadi, Z., \& Samani, R. (2018). The prevalence of anxiety and depression among people with infertility referring to Royan Institute in Tehran, Iran: A cross-sectional questionnaire study. Middle East Fertility Society Journal, 23(2), 103-106. https://doi.org/10.1016/j.mefs.2017.09.003

[43] Lukse, M. P., \& Vacc, N. A. (1999). Grief, Depression, and Coping in Women Undergoing Infertility Treatment. Obstet Gynecol, 93(2), 245-251. https://doi.org/10.1097/00006250-199902000-00017

[44] Hassan, H. (2018). Effectiveness of a structured teaching program on anxiety and perception regarding toxoplasmosis among seropositive pregnant women in Northern Upper Egypt. Clinical Nursing Studies, 6(1), 1-19. https://doi.org/10.5430/cns.v6n1p1 
[45] Hassan, H., Bayoumi, M., \& Atwa, A. (2016). Emotional Distress Associated with Gynecologic and Breast Cancer in Beni-Suef City. International Journal of Science and Research, 5(2), 1118-1129. https://doi.org/10.21275/v5i2.NOV161350

[46] Nargund, V. (2015). Effects of psychological stress on male fertility. Nat. Rev. Urol., 12, 373-382. https://doi.org/10.1038/nrurol.2015.112

[47] Parkitny, L., \& McAuley, J. (2010). The Depression Anxiety Stress Scale (DASS). Journal of Physiotherapy, 56(3), 204. Retrieved from http://www2.psy.unsw.edu.au/dass/over.htm

[48] Lovibond, F., \& Lovibond, S. H. (1995). Manual for the Depression Anxiety Stress Scales (2nd ed.). Sydney, Psychology Foundation. https://doi.org/10.1037/t01004-000

[49] Crawford, R., \& Henry, D. (2003). The Depression Anxiety Stress Scales (DASS): Normative data and latent structure in a large non-clinical sample. Brit $J$ Clin Psych, 42, 111-131. https://doi.org/10.1348/014466503321903544

[50] Brown, A., Chorpita, F., Korotitsch, W., \& Barlow, H. (1997). Psychometric properties of the Depression Anxiety Stress Scales (DASS) in clinical samples. Behav Res Ther, 35(1), 79-89. https://doi.org/10.1016/S0005-7967(96)00068-X

[51] Antony, M., Bieling, J., Cox, J., Enns, W., \& Swinson, P. (1998). Psychometric properties of the 42-item and 21-item versions of the Depression Anxiety Stress Scales in clinical groups and a community sample. Psychological Assessment, 10(2), 176-181. https://doi.org/10.1037/1040-3590.10.2.176

[52] Ian, P. C., Brian, J. C., \& Murray, W. E. (2001). Confirmatory Factor Analysis of the Depression-AnxietyStress Scales in Depressed and Anxious Patients. J Psychopathol Behav Asses, 23, 61-67. https://doi.org/10.1023/A:1011095624717

[53] Page, C., Hooke, R., \& Morrison, L. (2007). Psychometric properties of the Depression Anxiety Stress Scales (DASS) in depressed clinical samples. Br J Clin Psychol, 46, 283-297. https://doi.org/10.1348/014466506X158996

[54] Hassan, H. (2016). Call for psychosocial well-being among pregnant women associated with medical disorder in Beni-Suef governorate. IOSR Journal of Nursing and Health Science, 5(2), 81-94. https://doi.org/10.9790/1959-0502048194

[55] Pinar, S., \& Yildirim, G. (2006). Psychological, Social and Ethical Dimensions of Infertility: A review. International Journal Of Nursing Didatıcs, 6(11), 13-17.

[56] Parnian, R., Poorgholami, F., Parandavar, N., Jamali, S., \& Shakeri, F. (2017). A Comparative Study of Quality of Life in Infertile and Fertile Women Referred to Jahrom Infertility Clinics. Global Journal of Health Science, 9(4), 174-181. https://doi.org/10.5539/gjhs.v9n4p174

[57] Farzadi, L., \& Ghasemzadeh, A. (2008). sTwo main independent predictors of depression among infertile women: An Asian experience. Taiwan J Obstet Gynecol, 47(2), 163-167. https://doi.org/10.1016/S1028-4559(08)60074-1

[58] Drosdzol, A., \& Skrzypulec, V. (2009). Depression and anxiety among Polish infertile couples - an evaluative prevalence study. Journal of Psychosomatic Obstetrics \& Gynecology, 30(1), https://doi.org/10.1080/01674820902830276

[59] Upkong, D., \& Orji, E. (2006). Mental health of infertile women in Nigeria. 2006 Winter, 17(4), 259-65. https://doi.org/10.1016/S0084-3970(08)70253-6

[60] Muller, M. J. (1999). "Sexual Satisfaction in Male Infertility.". Archives of Andrology, 42, 138. https://doi.org/10.1080/014850199262797

[61] Donarelli, Z., Cocob, G., Gullo, S., Marino, A., Volpes, A., Salerno, L., \& Allegra, A. (2016). Infertility-related stress, anxiety and ovarian stimulation: can couples be reassured about the effects of psychological factors on biological responses to assisted reproductive technology? Reproductive BioMedicine and Society Online, 3, 16-23. https://doi.org/10.1016/j.rbms.2016.10.001

[62] Miall, E. (1994). Community constructs of involuntary childlessness: sympathy, stigma, and social support. $\begin{array}{llll}\text { Canadian review of sociology and anthropology, 31, 392-421. } & \text {. }\end{array}$ https://doi.org/10.1111/j.1755-618X.1994.tb00828.x 
[63] Malik, S., \& Coulson, N. (2008). The male experience of infertility: A thematic analysis of an online infertility support group bulletin board. Journal of Reproductive and Infant Psychology, 26(1), 18-30. https://doi.org/10.1080/02646830701759777

[64] Peronace, A., Jacky, B., \& Schmidt, L. (2007). Patterns of suffering and social interactions in infertile men: 12 months after unsuccessful treatment. Journal of Psychosomatic Obstetrics \& Gynecology, 28, 105-114. https://doi.org/10.1080/01674820701410049

[65] Zorn, B., Auger, J., Velikonja, V., Kolbezen, M., \& Meden-Vrtovec, H. (2007). Pychological factors in male partners of infertile couples: relationship with semen quality and early miscarriage. International Journal of Andrology, 31, 557-564. https://doi.org/10.1111/j.1365-2605.2007.00806.x

[66] Hassan, H., Saber, N., \& Sheha, E. (2019). Comprehension of Dyspareunia and Related Anxiety among Northern Upper Egyptian women: Impact of Nursing Consultation Context Using PLISSIT Model. Nursing \& Care Open Access Journal, 6(1), 1-19.

\section{Copyrights}

Copyright for this article is retained by the author(s), with first publication rights granted to the journal.

This is an open-access article distributed under the terms and conditions of the Creative Commons Attribution license (http://creativecommons.org/licenses/by/4.0/). 